NBER WORKING PAPER SERIES

\title{
AN EMPIRICAL ANALYSIS OF THE PRICING OF COLLATERALIZED DEBT OBLIGATIONS
}

\author{
Francis A. Longstaff \\ Arvind Rajan \\ Working Paper 12210 \\ http://www.nber.org/papers/w12210
NATIONAL BUREAU OF ECONOMIC RESEARCH
1050 Massachusetts Avenue
Cambridge, MA 02138
May 2006

Longstaff: Allstate Professor of Insurance and Finance, UCLA Anderson School and the NBER. Rajan: Managing Director, Relative Value Trading, Citigroup. We are grateful for helpful discussions with Keith Crider, Darrell Duffie, Youseff Elouerkhaoui, Mitch Janowski, L. Sankarasubrahmanian, Alan Shaffran, David Shelton, Jure Skarabot, Ken Singleton, and Ryoichi Yamabe. We are particularly grateful to Holger Kraft for valuable comments and suggestions. We also thank Guarav Bansal and Yuzhao Zhang for research assistance. All errors are our responsibility. The views expressed herein are those of the author(s) and do not necessarily reflect the views of the National Bureau of Economic Research.

(O2006 by Francis A. Longstaff and Arvind Rajan. All rights reserved. Short sections of text, not to exceed two paragraphs, may be quoted without explicit permission provided that full credit, including $\odot$ notice, is given to the source. 
An Empirical Analysis of the Pricing of Collateralized Debt Obligations

Francis A. Longstaff and Arvind Rajan

NBER Working Paper No. 12210

May 2006

JEL No. G1

\begin{abstract}
We study the pricing of collateralized debt obligations (CDOs) using an extensive new data set for the actively-traded CDX credit index and its tranches. We find that a three-factor portfolio credit model allowing for firm-specific, industry, and economywide default events explains virtually all of the time-series and crosssectional variation in CDX index tranche prices. These tranches are priced as if losses of $0.4,6$, and 35 percent of the portfolio occur with expected frequencies of 1.2, 41.5, and 763 years, respectively. On average, 65 percent of the CDX spread is due to firm-specific default risk, 27 percent to clustered industry or sector default risk, and 8 percent to catastrophic or systemic default risk. Recently, however, firm-specific default risk has begun to play a larger role.
\end{abstract}

Francis A. Longstaff

UCLA

Anderson Graduate School of Management

110 Westwood Plaza, Box 951481

Los Angeles, CA 90095-1481

and NBER

francis.longstaff@anderson.ucla.edu 


\section{INTRODUCTION}

In its most basic form, a collateralized debt obligation (CDO) is simply a financial claim to the cash flows generated by a portfolio of debt securities or, equivalently, a basket of credit default swaps (CDS contracts). Thus, CDOs can be viewed as the credit-market counterparts to the familiar collateralized mortgage obligations (CMOs) actively traded in secondary mortgage markets.

Since its inception in the mid 1990s, the market for CDOs has become one of the most-rapidly-growing financial markets ever. Industry sources estimate the size of the CDO market at the end of 2005 to be in excess of $\$ 1.5$ trillion. Important reasons for the rapid growth in the $\mathrm{CDO}$ market include the recent introduction of market indexes such as the highly-successful CDX and Itraxx credit indexes and the emergence of active trading in standardized tranches on these credit indexes. Another important driving force is the parallel growth in the closely-related CDS and credit derivatives market which the International Swaps and Derivatives Association (ISDA) estimates reached $\$ 12.43$ trillion notional in mid-2005. Recently, CDOs have been in the spotlight because of the May 2005 credit crisis in which downgrades of Ford's and General Motors' debt triggered a wave of large CDO losses among many credit-oriented hedge funds and major Wall Street dealers.

This paper conducts an empirical analysis of the market prices of standardized tranches on the CDX credit index using an extensive data set recently made available to us by Citigroup. To the best of our knowledge, this is the first large-scale empirical study of CDO pricing to appear in the academic literature. As such, our first task will be to provide the reader with an introduction to the CDO market and describe the fundamental characteristics of index tranche pricing. The data used in the study cover almost the entire period since the inception of the CDX credit index.

Motivated by an important recent paper by Duffie and Gârleanu (2001) on the valuation of CDOs, we develop a three-factor portfolio credit model for pricing CDOs. In the Duffie and Gârleanu framework, three types of default events are possible: idiosyncratic or firm-specific defaults, industrywide defaults in a specific sector of the economy, and economywide defaults affecting virtually every industry and sector. Rather than focusing on the individual "quantum" or "zero-one" states of default for each firm and aggregating up to the portfolio level, however, this framework takes a "statistical mechanics" approach by modeling portfolio credit losses directly. Specifically, we allow portfolio losses to occur as the realizations of three separate Poisson 
processes, each with a different jump size and intensity process. Thus, realizations of the three Poisson events can be mapped directly into the three types of default events in the Duffie and Gârleanu framework. We take the model to the data by fitting it to the CDX index spread and the prices of the $0-3,3-7,7-10,10-15$, and $15-30$ percent CDX index tranches for each date during the sample period.

We first address the issue of how many factors are actually needed to explain the pricing of CDOs. To do this, we also estimate one-factor and two-factor versions of the model. We then use a likelihood ratio approach to test whether the two-factor model has significant incremental explanatory power relative to the one-factor model and, likewise, whether the three-factor model has significant incremental explanatory power relative to the two-factor model. We find that the three-factor model significantly outperforms the two-factor model which, in turn, significantly outperforms the onefactor model. These results provide direct evidence that the market expects defaults for the firms in the CDX index to cluster (correlated defaults) and strongly supports the Duffie and Gârleanu credit modeling framework.

Focusing on the three-factor results, we find that the estimated jump sizes for the three Poisson processes are on the order of $0.4,6$, and 35 percent, respectively. Since there are 125 firms in the CDX index, the jump size of 0.4 percent for the first Poisson process can be interpreted as the portfolio loss resulting from the default of a single firm, given a 50 percent recovery rate $(1 / 125 \times 0.50=0.004)$. The jump size of 6 percent for the second Poisson process can be interpreted as an event in which, say, 15 firms default together. Since this represent roughly 10 percent of the firms in the portfolio, this event could be viewed as a major crisis that pushes an entire industry or sector into financial distress. Finally, the 35 percent jump size for the third Poisson process has the interpretation of a catastrophic event that wipes out the majority of firms in the economy. Our analysis indicates that all three types of credit risk are present in the market and are important determinants of the pricing of CDOs.

We also estimate the probabilities or intensities of the three Poisson events (under the risk-neutral pricing measure). On average, the expected time until an idiosyncratic or firm-specific default is 1.2 years, the expected time until an industrywide default crisis is 41.5 years, and the expected time until a catastrophic economywide default event is 763 years. We find, however, that the implied probability of an industry or economywide default event increased dramatically during the hedge fund credit crisis in May 2005 triggered by the rating downgrades of Ford and General Motors.

Using the intensity estimates, we decompose the CDX index spread into its three components. We find that on average, firm-specific default risk represents only 64.6 percent of the total CDX index spread, while industry and economywide default risks represent 27.1 and 8.3 percent of the index spread, respectively. Thus, the risk of industry or economywide financial distress accounts for more than one-third of the default risk in the CDX portfolio. Recently, however, idiosyncratic default risk has played a larger role. By definition, the same decomposition holds for the default 
spreads of the typical firm in the index. Thus, the event that a firm defaults can be partitioned into three events: the event that only the firm defaults, the event that the firm and a number of other firms in the same industry or sector default together, and the catastrophic event in which the majority of firms in the economy default together.

We then examine how well the model captures the pricing of individual index tranches. Even though tranche spreads are often measured in hundreds or even thousands of basis points, the root-mean-squared error (RMSE) of the three-factor model is typically on the order of only two to three basis points, which is well within the typical bid-ask spreads in the market. Thus, virtually all of the time-series and crosssectional variation in index tranche prices is captured by the model. We find that the largest pricing errors occurred shortly after the inception of the CDX index and tranche market, but decreased rapidly after several weeks. Thus, despite some early mispricing, the evidence suggests that the CDX index tranche market quickly evolved into a more efficient market. We also examine the extent to which dispersion in the credit spreads of individual firms within the CDX index affect the pricing of CDOs. We show that spread dispersion has a strong effect on the implied volatility of the loss distribution even after holding fixed the effect on the CDX index spread.

The paper contributes to the rapidly growing literature on credit derivatives and correlated defaults. Important recent contributions in this area include Duffie and Gârleanu (2001), Bakshi, Madan, and Zhang (2004), Jorion and Zhang (2005), Longstaff, Mithal, and Neis (2005), Das, Duffie, Kapadia, and Saita (2005), Das, Freed, Geng, and Kapadia (2005), Saita (2005), Yu (2005a, 2005b), Duffie, Saita, and Wang (2006), and many others. This paper differentiates itself by using the information in CDX index tranches to provide direct measures of the degree of default clustering or correlation incorporated into the market prices of credit derivatives.

The remainder of this paper is organized as follows. Section 2 provides an introduction to the CDO market. Section 3 describes the data used in the study. Section 4 presents the three-factor portfolio credit model. Section 5 applies the model to the valuation of index tranches. Section 6 reports the results from the empirical analysis. Section 7 summarizes the results and makes concluding remarks.

\section{AN INTRODUCTION TO CDOs}

CDOs have become one of the most important new financial innovations of the past decade. It is easiest to think of a CDO as a portfolio containing certain debt securities as assets, and multiple claims in the form of issued notes of varying seniority. The liabilities are serviced using the cash flows from the assets, as in a corporation. Although CDOs existed in various forms previously, it was only in the mid-1990s that they began to be popular. Over subsequent years, issuance experienced exponential growth until 2000, and has continued to grow at about 10 percent annually since them. An- 
nual issuance now exceeds $\$ 100$ billion, and the assets securitized by cash CDOs have broadened to include investment-grade bonds, high yield bonds, emerging market securities, leveraged loans, middle market loans, trust preferred securities, asset-backed securities, commercial mortgages, and even previously issued CDO tranches. CDOs play an increasingly important economic role in the markets, allowing portfolio credit risk and return to be redistributed according to demand among various global investors with lower and higher risk appetite. ${ }^{1}$

Over the past few years, the technology of cash CDOs has merged with the technology of credit derivatives to create the so-called synthetic CDO, which is the main focus of this paper. Synthetic CDOs differ from cash CDOs in that the portfolios that provide the cash flow to service their liabilities consist of credit default swaps rather than bonds or other cash securities. The majority of synthetic securities are based on corporate credit derivatives, and tend to be simpler (and hence more amenable to mathematical modeling).

\subsection{An Example of a Stylized CDO.}

To build up understanding of a full fledged synthetic CDO, we will begin with a simpler example based on a $\$ 100$ million investment in a diversified portfolio of fiveyear par corporate bonds. Imagine that a financial institution (CDO issuer) sets up this portfolio, which consists of 100 separate bonds, each with a market value of $\$ 1$ million, and each issued by a different firm. Imagine also that every bond in the portfolio is rated BBB and has a coupon spread over Treasuries of 100 basis points. The CDO issuer can now sell five-year claims against the cash flows generated by the portfolio. These claims are termed CDO tranches and are constructed to vary in credit risk from very low (senior tranches) to low (junior or mezzanine tranches) to very high (the "equity" tranche).

Let us illustrate a typical CDO structure by continuing the example. First, imagine that the CDO issuer creates a so-called equity tranche with a total notional amount of three percent of the total value of the portfolio ( $\$ 3$ million). By definition, this tranche absorbs the first three percent of any defaults on the entire portfolio. In exchange, this tranche may receive a coupon rate of, say, 2500 basis points above Treasuries. If there are no defaults, the holder of the equity tranche earns a high coupon rate for five years and then receives back his $\$ 3$ million notional investment. Now assume that one of the 100 firms represented in the portfolio defaults (and also that there is zero recovery in the event of default). In this case, the equity tranche absorbs the $\$ 1$ million loss to the portfolio and the notional amount of the equity tranche is reduced to $\$ 2$ million. Thus, the equity tranche holder has lost one-third of his investment. Going forward, the equity tranche investor receives the 2500 basis

${ }^{1}$ For additional insights into the CDO market, see the excellent discussions provided by Duffie and Gârleanu (2001), Duffie and Singleton (2003), Roy and Shelton (2004), and Li, Roy, and Skarabot (2004). 
point coupon spread as before, only now only on his $\$ 2$ million notional position. Now assume that another two firms default. In this case, the equity tranche absorbs the additional losses of $\$ 2$ million, the notional amount of the equity tranche investor's position is completely wiped out, and the investor receives neither coupons nor principal going forward. Because a three-percent loss in the portfolio translates into a 100percent loss for the equity tranche investor, we can view the equity tranche investor as being leveraged $331 / 3$ to 1 .

Now imagine that the CDO issuer also creates a junior mezzanine tranche with a total notional amount of four percent of the total value of the portfolio ( $\$ 4$ million). This tranche absorbs up to four percent of the total losses on the entire portfolio after the equity tranche has absorbed the first three percent of losses. For this reason, this tranche is designated the 3-7 percent tranche. In exchange for absorbing these losses, this tranche may receive a coupon rate of, say, 300 basis points above Treasuries. If total credit losses are less than three percent during the five-year horizon of the portfolio, then the 3-7 percent investor earns the coupon rate for five years and then receives back his $\$ 4$ million notional investment. If total credit losses are greater than or equal to seven percent of the portfolio, the total notional amount for the $3-7$ percent investor is wiped out.

The CDO issuer follows a similar process in creating additional mezzanine, senior mezzanine, and even super-senior mezzanine tranches. A typical set of index CDO tranches might include the $0-3$ percent equity tranche, and $3-7,7-10,10-15,15-30$, and 30-100 percent tranches. The initial levels 3, 7, 10, 15, and 30 percent at which losses begin to accrue for the respective tranches are called attachment points or subordination levels. Note that the total notional valuation of all the tranches equals the $\$ 100$ million notional of the original portfolio of corporate bonds. In addition, the total coupon payments to all tranches must equal the total coupon flow from the entire underlying portfolio. For example, if the coupon spreads on the $0-3,3-7,7-10$, $10-15,15-30$, and 30-100 tranches were 2500, 300, 50, 30, 20, and 10, respectively, then the weighted-average coupon spread of .03 $\times 2500+.04 \times 300+.03 \times 50+.05 \times$ $30+.15 \times 20+.70 \times 10=100$ basis points would equal the total coupon spread of the overall portfolio.

An interesting aspect of the CDO creation process is that because each tranche has a different degree of credit exposure, each tranche would have its own credit rating. For example, the super-senior 30-100 percent tranche can only suffer credit losses if total losses on the underlying portfolio exceed 30 percent of the total notional amount. Since this is highly unlikely, this super-senior tranche would typically have a AAA rating. In contrast, the highly-subordinated 3-7 percent mezzanine tranche might carry a below-investment-grade rating as a reflection of its junior status in the "capital structure" of the overall portfolio. In general, the credit rating of a tranche should be similar to those for ordinary corporate bonds with similar coupon spreads. For example, a 7-10 percent tranche with a coupon spread of 50 basis points will likely 
have a rating similar to corporate bonds with comparable coupon spreads. Note that if an issuer purchases the underlying bond portfolio, and then sells off each individual tranche, the issuer no longer has any net economic exposure to credit events in the portfolio (this is referred to as selling the entire capital structure).

This example also illustrates one of the most important economic functions that the CDO tranching process fulfills. Specifically, in today's global economy, the average rating of corporate debt is $\mathrm{BBB}$, whereas the average risk appetite of fixed-income investors in aggregate is much lower. Most fixed income investors typically require a high degree of safety of principal, and include many ultra-risk averse investors such as central banks. The growth in the savings of today's global economy, which is predominantly being generated in Asian and petrodollar countries, is bar-belled in its risk appetite, seeking either the safety of a AAA rating or equity-like (10 percent-plus) returns. Yet the universe of AA and AAA rated individual corporate bonds is quite small. CDO technology has evolved essentially in order to match these demands with the available profile of fixed-income assets. By issuing CDOs from portfolios of A and BBB grade bonds, financial intermediaries can create a larger pool of AAA rated securities. In the example above, up to 90 percent of the tranches constructed (from 10-15 percent to 30-100 percent) would likely be rated AAA, and another three percent (7-10 percent) would likely be rated AA. Thus, the CDO process would serve to complete the financial market by creating high-credit-quality securities that would otherwise not exist in the market.

\subsection{Synthetic CDOs.}

To take advantage of the wide availability of credit derivatives, credit markets have recently introduced CDO structures known as synthetic CDOs. This type of structure has become very popular and the total notional amount of synthetic CDO tranches is growing rapidly. A synthetic CDO is economically similar to a cash CDO in most respects. The principal difference is that rather than there being an underlying portfolio of corporate bonds on which tranches are based, the underlying portfolio is actually a basket of credit default swap contracts. Recall that a CDS contract functions as an insurance contract in which a buyer of credit protection makes a fixed payment each quarter for some given horizon such as five years. If there is a default on the underlying reference bond during that period, however, then the buyer of protection is able to give the defaulted bond to the protection seller and receive par (the full face value of the bond). Thus, the first step in creating a synthetic CDO is to define the underlying basket of CDS contracts.

\subsection{Credit Default Indexes and Index Tranches.}

In this study, we focus on CDOs with cash flows tied to the most liquid U.S. corporate credit derivative index, the DJ CDX North American Investment Grade Index. This index is managed by Dow Jones and is based on a liquid basket of CDS contracts for 125 U.S. firms with investment grade corporate debt. The CDX index itself trades 
just like a single-name CDS contract, with a defined premium based on the equallyweighted basket of its 125 constituents. The individual firms included in the CDX basket are updated and revised ("rolled") every six months in March and September, with a few downgraded and illiquid names being dropped and new ones taking their places. CDX indexes are numbered sequentially. Thus, the index for the first basket of 125 firms was designated the CDX NA IG 1 index in 2003, the index for the second basket of 125 firms the CDX NA IG 2 index, etc., and so on up to CDX NA IG 5 in September 2005. While there is considerable overlap between successive CDX NA IG indexes, there can occasionally be significant changes across index rolls. For example, the CDX NA IG 4 index (beginning in March 2005) includes Ford and General Motors while the CDX NA IG 5 index (beginning in September 2005) does not since the debt for these firms dropped below investment grade in May 2005.

Index CDO tranches have also been issued, each tied to a specific CDX index. The attachment points of these CDO tranches are standardized at 3, 7, 10, 15, and 30 percent, exactly as in the example above. To illustrate how a index CDO tranche works, let us use the numbers from our previous example - but instead of bonds, using the CDX index with a market premium of 50 basis points consisting of 125 CDS contracts of $\$ 1$ million each (index notional of $\$ 125$ million). Suppose the equity tranche holder receives a coupon spread of 2500 basis points. If a default occurs in one of the 125 index names, however, the equity tranche holder faces the same cash outflows as the protection seller in a CDS contract on the defaulting firm. Specifically, the equity tranche investor would have a cash outflow of $\$ 1$ million dollars if the recovery of principal (the value of the debt obligation delivered by the protection buyer) is zero percent, and the notional amount on which future coupon cash flows are based would be reduced to $\$ 2$ million (exactly as in the cash CDO example). In a similar manner, the equity index tranche investor would bear the entire losses of any subsequent defaults (up to her notional exposure) just as if she were the protection seller in CDS contracts on the defaulting firms. In essence, we can view the cash outflows to the various index tranche investors as the equivalent of being the protection seller on the first three to default, on the fourth through seventh to default, the eighth through tenth to default, etc. Thus, the initial coupon spread on each tranche is held fixed over time (but applied to the remaining notional amount within each tranche).

Since these instruments are structured as credit default swaps, when an investor "buys" a synthetic index tranche from a counterparty, they are selling protection on that tranche. Their counterparty has bought protection on the same tranche from them. This highlights a convenient feature of these index tranches - that is, a dealer need not create and sell the entire capital structure of tranches to investors; rather investors are free to synthetically create and trade (sell or buy) individual index tranches (single-tranche index CDOs) according to their needs. For example two investors can trade protection on the 3-7 percent tranche of the DJ CDX 5 index with each other without anyone having to create the $0-3$ percent, $7-10$ percent and other tranches. As observed earlier, the losses on an $N-M$ percent tranche are zero if the total losses 
on the underlying portfolio are less than $N$. On the other hand, the total losses on the tranche are 1.00 or 100 percent if the total losses on the underlying portfolio equals or exceeds $M$. For underlying portfolio losses between $N$ and $M$, tranche losses are linearly interpolated between zero and one. Because of this, the losses on a $N-M$ percent tranche can be viewed intuitively as a call spread on the total losses of the underlying portfolio. This intuition will be formalized in a later section. Just as an option has a "delta", that is, an equivalent exposure to the underlying, the tranche has a delta with respect to its underlying index.

The simplicity of construction, the liquidity of the underlying CDX indexes, the standardization of attachment points, the availability of tranche pricing models, and the freedom from creating the full capital structure have all contributed to a great increase in the volume of trading in index tranches. Therefore, in the past few years, index tranches have become liquidly traded and quotes and data for them are available from many dealers in the market daily.

\subsection{Other Synthetic CDOs.}

Although index tranches are the most liquid synthetic tranches, a synthetic tranche can be based on any portfolio. A tranche created with a specific non-index portfolio, and with customized attachment points, e.g. 5-8 percent, is called a bespoke portfolio. Investors use bespoke tranches to buy or sell specific slices of protection on specific portfolios that they wish to express views on. For example, an investor selling protection on the $0-4$ percent equity tranche of a BB rated portfolio might be expressing a bullish point of view on the likelihood of defaults in his favorite basket of highyield credits, while another investor buying protection on a 5-10 percent basket of 75 investment-grade names might be buying "out-of-the-money" catastrophe protection on a portfolio she owns (since the likelihood of five percent or more of default-related losses in an investment grade portfolio in five years is quite small). While the results in this paper are based on index tranche data, the analysis can equally well be applied to most bespoke CDO tranches. Finally, there are also full capital structure synthetic CDOs, created when demand exists for all parts of the capital structure. Provided a CDO observes the simple type of structure we specified in the example, a model such as the one in this paper may be used to price its tranches. ${ }^{2}$

\footnotetext{
${ }^{2}$ The analysis in this paper, however, may not apply directly to certain other types of portfolio derivative products, for example $N$ th-to-default baskets, CDO-squareds, and cash CDOs, which have more granular compositions, more complex structures, or more difficult-to-model cash flows and rules, respectively.
} 


\section{THE DATA}

CDOs are a relatively new financial innovation and have only recently begun to trade actively in the markets. Because of this, it has been difficult for academic researchers to obtain reliable CDO pricing data. We were fortunate, however, to be given access by Citigroup to one of the most extensive proprietary data sets of CDO index and tranche pricing data in existence.

The data consist of daily closing values for the five year CDX NA IG index (CDX index for short) for the period from October 2003 to October 2005. As discussed earlier, the underlying basket of 125 firms in the index is revised every March and September. Thus, the index data is actually for the five individual indexes denoted CDX $i, i=1,2,3,4$, and 5 . This data set covers virtually the entire history of the CDX index. ${ }^{3}$ For the primarily descriptive purposes of this section, we report summary statistics based on the continuous series of the on-the-run CDX index (rather than reporting statistics separately for the individual CDX series). There are a total of 435 daily observations available during the sample period

In addition to the index data, we also have daily closing quotation data for the $0-3,3-7,7-10,10-15$, and $15-30$ percent tranches on the CDX index. The pricing data for most tranches are in terms of the basis point premium paid to the CDO investor for absorbing the losses associated with the individual tranches. Thus, a price of 300 for the 3-7 percent tranche implies that the tranche investor would receive a premium of 300 basis points per year paid quarterly on the remaining balance in exchange for absorbing the default losses from three to seven percent on the CDX index. The exception is the market convention for the equity tranche (the $0-3$ percent tranche) which is generally quoted in terms of points up front. Specifically, a price of 50 for this tranche means that an investor would need to receive $\$ 50$ up front per $\$ 100$ notional amount, plus an premium of 500 basis points per year paid quarterly on the remaining balance, to absorb the first three percent of losses on the CDX index. Rather than using this market convention, however, we convert the points up front into spread equivalents to facilitate comparison with the pricing data for the other tranches.

In addition to the CDX index and tranche data, we also collect daily New York closing data on 3-month, 6-month, 12-month Libor rates, and on 2-year, 3-year, 5year, 7-year, and 10-year swap rates. The Libor data is obtained from the Bloomberg system. The swap data is obtained from the Federal Reserve Board's web site. From this Libor spot rate and swap par rate data, we use a standard cubic spline approach to bootstrap zero-coupon curves that will be used throughout the paper to discount

\footnotetext{
${ }^{3}$ Data is missing for some days during the earlier part of the sample. We omit these days from the sample.
} 
cash flows. ${ }^{4}$ Since the same zero-coupon curve is used to discount both legs of the CDO contract, however, the results are largely insensitive to the decision to discount using the Libor-swap curve; the results are virtually identical when the bootstrapped Treasury curve is used for discounting cash flows.

Table 1 provides summary statistics for the index and tranche data. As shown, the average values of the spreads are monotone decreasing in seniority (attachment point). The average spread for the $0-3$ percent equity tranche is 1758.87 basis points (which translates into an average number of points up front of 39.34). This spread is many times larger than the average spread for the junior mezzanine $3-7$ percent tranche, reflecting that the expected losses for the equity tranche are much higher than for more senior tranches. Similar comparisons hold for all the other tranches. Figure 1 plots the time series of tranche spreads for the various attachment points.

To explore how closely the spreads for the various index tranches move together, Table 2 reports the correlations for daily changes in the spreads. As indicated, there is an almost perfect correlation between the CDX index spread itself and the spread on the $0-3$ percent equity tranche. This is understandable given that both would be impacted by the first few defaults in the portfolio. In contrast, the correlations between the CDX index spread and the mezzanine tranches range from about 0.67 to 0.80. The correlations between the equity tranche and the various mezzanine tranches range from about 0.65 to 0.76 . This indicates that while these spreads have a high degree of correlation, there is considerable independent variation in the spreads of the mezzanine tranches. The correlations among the mezzanine tranches themselves are also relatively high, but are clearly far from perfect. These correlations tend to be in the range of 0.65 to 0.90 . Thus, the correlations are generally stronger between adjacent parts of the capital structure, e.g. equity and junior mezzanine, senior and super-senior mezzanine, and weaker between tranches that are further apart, e.g. equity and super-senior mezzanine. This is intuitive since we might expect continuity in the implied loss distribution across tranche boundaries, and demand for adjacent tranches has overlap among investor segments. These results suggests that the index tranche spreads are driven by multiple factors.

To provide a more formal analysis of this latter point, we conduct a simple principal components analysis of the correlation matrix of changes in the respective tranche spreads. The results from this principal components analysis are consistent with the features of the correlation matrix described above. The first principal component explains 81.8 percent of the variation in spreads and is an equity/junior mezzanine factor. Essentially, this factor appears to shift risk back and forth between the junior and senior parts of the capital structure. The second principal component explains an additional 7.4 percent of the variation and is primarily a senior mezzanine factor.

${ }^{4}$ See Longstaff, Mithal, and Neis (2005) for a more detailed discussion of this bootstrapping algorithm. 
The third principal component explains an additional 5.7 percent of the variation and represents a spread between the equity and mezzanine tranches. Together, the first three principal components explain a total of 94.9 percent of the total variation in CDX index tranche spreads. Figure 2 plots the first three principal components.

\section{THE MODEL}

In an important recent paper on modeling CDOs, Duffie and Gârleanu (2001) provide an intuitive theoretical framework for valuing CDO tranches. In their framework, the intensity process governing defaults of individual firms has three distinct components: a marketwide component affecting all firms, an industry or sector component affecting a subset of firms, and a firm-specific or idiosyncratic factor. In addition, they present a general jump-diffusion specification for the risk-neutral dynamics of these components. The results from the principal components analysis in the previous section are very consistent with the structure of the Duffie and Gârleanu approach. Motivated by their work, we develop an intuitive valuation model for index tranches that incorporates the economic structure of their framework while adapting itself to the unique features of this market.

To explain the logic behind this model, it is useful to first make a short digression into the modeling of stock index options (such as options on the S\&P 100). In theory, one could model S\&P 100 index options by specifying the dynamics of each of the 100 firms in the index and then evaluating a 100-dimensional expectation. In reality, of course, such an approach would be too cumbersome to be useful or practical. Rather, the standard approach to valuing index options is to take a more "macro" perspective and model the dynamics of the index directly.

To date, most modeling of CDOs has likewise been done at an individual firm level. Typically, practitioners model the losses on, say, the 125-firm portfolio underlying the CDX index by first simulating the dynamics of each firm, checking whether each firm is in the "quantum" or "zero-one" state of default, and then aggregating losses over the entire portfolio. As discussed earlier, however, losses on the tranches are simple functions of the total losses on the underlying portfolio. Thus, the distribution of total portfolio losses represents a "sufficient statistic" for valuing tranches (just as the distribution of the stock index is sufficient for pricing stock index options). Accordingly, rather than modeling individual "quantum" defaults, we will follow a "statistical mechanics" based approach of modeling the distribution of total portfolio losses directly.

In doing this, it is important to stress that we are not implying that individual firm-level information about default status is unimportant. In fact, for many types of credit derivatives (such as credit default swaps or first-to-default swaps on small baskets of firms), individual firm default status is essential in defining the cash pay- 
offs. Rather, we suggest that for many other types of credit related contracts that are tied to larger portfolios, the "reduced-form" approach of modeling portfolio-level losses directly may provide important advantages such as simplicity, transparency, and tractability with little loss in our ability to capture the underlying economics. In general, the smaller the single-name risk concentration in a portfolio, the more applicable is the aggregate loss approach taken here.

Let $L_{t}$ denote the total portfolio losses on the CDX portfolio per $\$ 1$ notional amount. By definition, $L_{0}=0$. To model the dynamic evolution of $L_{t}$ we assume

$$
\frac{d L_{t}}{1-L_{t}}=\bar{\gamma}_{1} d N_{1 t}+\bar{\gamma}_{2} d N_{2 t}+\bar{\gamma}_{3} d N_{3 t}
$$

where $\bar{\gamma}_{i}=1-e^{-\gamma_{i}}, i=1,2,3$, where $\gamma_{1}, \gamma_{2}$, and $\gamma_{3}$ are nonnegative constants defining jump sizes, and where $N_{1 t}, N_{2 t}$, and $N_{3 t}$ are independent Poisson processes. Note that for small values of $\gamma_{i}$, the jump size $\bar{\gamma}_{i}$ is essentially just $\gamma_{i}$. Thus, for expositional simplicity, we will take a slight liberty and generally refer to the parameters $\gamma_{1}, \gamma_{2}$, and $\gamma_{3}$ simply as jump sizes. Integrating Equation (1) and conditioning on time-zero values (a convention we adopt throughout the paper) gives the general solution for $L_{t}$

$$
L_{t}=1-e^{-\gamma_{1} N_{1 t}} e^{-\gamma_{2} N_{2 t}} e^{-\gamma_{3} N_{3 t}} .
$$

From this equation, it can be seen that the economic condition $0 \leq L_{t} \leq 1$ is satisfied for all $t$. Furthermore, since $N_{1 t}, N_{2 t}$, and $N_{3 t}$ are nondecreasing processes, the intuitive requirement that total losses be a nondecreasing function of time is also satisfied. ${ }^{5}$

These dynamics imply that there are three factors at work in generating portfolio losses. To illustrate how these factors affect total losses, assume that the three jump sizes are $0.01,0.10$, and 0.50 , respectively, and that there is zero recovery in the event of a default. When a jump in the first Poisson process occurs, the portfolio experiences a one-percent loss. Thus, a realization of the first Poisson process could be viewed as an isolated default affecting only one firm. In contrast, a realization of the second Poisson process results in a portfolio loss of 10 percent. Thus, this event could be interpreted as the impact of a major event that decimates the ranks of firms in a specific sector or industry. Similarly, when a jump in the third Poisson process

${ }^{5}$ Because portfolio losses on the CDX portfolio consist of payments to protection buyers, it is difficult to imagine a realistic set of circumstances where total losses would actually decline over time. It would not be sufficient for a defaulted bond to subsequently increase in value since the cash flow to the protection buyer is made at a specific point in time. Rather, it would require that a protection payment made on a CDS contract be reversed and rebated back to the protection seller. 
occurs, 50 percent of the remaining firms in the portfolio default, corresponding to the realization of some catastrophic event affecting the entire economy. Thus, the model allows for both idiosyncratic or firm-specific default as well as for the broader systemic risk of multiple defaults within an industry or throughout the economy. This framework is consistent with the multifactor structure of the model presented in Duffie and Gârleanu (2001).

The fact that the model incorporates both firm-specific and multiple-firm defaults allows the model to capture the notion of default correlation. To see this, consider the hypothetical situation in which the intensities of the second and third Poisson processes were zero. In this case, only idiosyncratic or uncorrelated defaults could occur. At the other extreme, consider the situation where the intensities of the first and second Poisson processes are zero. In this situation, only highly correlated systemic defaults could occur in the economy. In between these two extremes, a full spectrum of possible default correlations could arise based on the relative magnitudes of the intensities of the Poisson processes.

The intensities of the three Poisson processes are designated $\lambda_{1 t}, \lambda_{2 t}$, and $\lambda_{3 t}$, respectively. To complete the specification of the model, we assume that the dynamics for the intensity processes are given by,

$$
\begin{aligned}
& d \lambda_{1 t}=\left(\alpha_{1}-\beta_{1} \lambda_{1 t}\right) d t+\sigma_{1} \sqrt{\lambda_{1 t}} d Z_{1 t} \\
& d \lambda_{2 t}=\left(\alpha_{2}-\beta_{2} \lambda_{2 t}\right) d t+\sigma_{2} \sqrt{\lambda_{2 t}} d Z_{2 t} \\
& d \lambda_{3 t}=\left(\alpha_{3}-\beta_{3} \lambda_{3 t}\right) d t+\sigma_{3} \sqrt{\lambda_{3 t}} d Z_{3 t}
\end{aligned}
$$

where $Z_{1 t}, Z_{2 t}$, and $Z_{3 t}$ are standard independent Brownian motion processes. These dynamics insure that the intensities for the three Poisson processes are always nonnegative. Furthermore, since these intensities are stochastic, it is clear from the previous discussion that this framework allows default correlations to vary over time.

To value claims that depend on the realized losses on a portfolio, we first need to determine the distribution of $L_{t}$. From Equation (2), $L_{t}$ is a simple function of the values of the three Poisson processes. Thus, it is sufficient to find the distributions for the individual Poisson processes, since expectations of cash flows linked to $L_{t}$ can be evaluated directly with respect to the distributions of $N_{1 t}, N_{2 t}$, and $N_{3 t}$.

Since many of the following results are equally applicable to each of the three Poisson processes, we will simplify notation whenever possible by dropping the subscripts 1, 2, and 3 when we present generic results and the interpretation is clear from context. Standard results imply that, conditional on the path of $\lambda_{t}$, the probability of $N_{T}=i, i=0,1,2, \ldots$, can be expressed as 


$$
\frac{\exp \left(-\int_{0}^{T} \lambda_{t} d t\right)\left(\int_{0}^{T} \lambda_{t} d t\right)^{i}}{i !}
$$

Let $P_{i}(\lambda, T)$ denote $i$ ! times the probability that $N_{T}=i$, conditional on the current (the time-zero unsubscripted) value of $\lambda$. Thus,

$$
P_{i}(\lambda, T)=E\left[\exp \left(-\int_{0}^{T} \lambda_{t} d t\right)\left(\int_{0}^{T} \lambda_{t} d t\right)^{i}\right]
$$

For $i=0$, the Appendix shows that this expression is easily solved in closed form from results in Cox, Ingersoll, and Ross (1985). For $i>0$, the results in Karlin and Taylor (1981), pp. 202-204 can be used to show that $P_{i}(\lambda, T)$ satisfies the recursive partial differential equation,

$$
\frac{\sigma^{2} \lambda}{2} \frac{\partial^{2} P_{i}}{\partial \lambda^{2}}+(\alpha-\beta \lambda) \frac{\partial P_{i}}{\partial \lambda}-\lambda P_{i}+i \lambda P_{i-1}=\frac{\partial P_{i}}{\partial T} .
$$

The Appendix shows that this partial differential equation for $P_{i}(\lambda, T)$ can be solved in closed form to give,

$$
P_{i}(\lambda, T)=A(T) e^{-B(T) \lambda} \sum_{j=0}^{i} C_{i, j}(T) \lambda^{j},
$$

where

$$
\begin{aligned}
& A(T)=\exp \left(\frac{\alpha(\beta-\xi) T}{\sigma^{2}}\right)\left(\frac{2 \xi}{\beta+\xi-(\beta-\xi) e^{-\xi T}}\right)^{\frac{2 \alpha}{\sigma^{2}}} \\
& B(T)=\frac{2 \xi(\beta+\xi)}{\sigma^{2}\left(\beta+\xi-(\beta-\xi) e^{-\xi T}\right)}-\frac{\beta+\xi}{\sigma^{2}}
\end{aligned}
$$

and $\xi=\sqrt{\beta^{2}+2 \sigma^{2}}$. The first $C_{i, j}(T)$ function is $C_{0,0}(T)=1$. The remaining $C_{i, j}(T)$ functions are given as solutions of the recursive system of first-order ordinary differential equations, 


$$
\begin{aligned}
& \frac{d C_{i, i}}{d t}=i C_{i-1, i-1}-\left(\sigma^{2} B(t)+\beta\right) i C_{i, i}, \\
& \frac{d C_{i, j}}{d t}=i C_{i-1, j-1}-\left(\sigma^{2} B(t)+\beta\right) j C_{i, j}+(j+1)\left(\alpha+j \sigma^{2} / 2\right) C_{i, j+1}, \\
& \frac{d C_{i, 0}}{d t}=\alpha C_{i, 1},
\end{aligned}
$$

where $1 \leq j \leq i-1$. These differential equations are easily solved numerically subject to the initial condition that $C_{i, j}(0)=0$ for all $i>0$.

With these solutions, the expectation of an arbitrary function $F\left(L_{t}\right)$ of the portfolio losses (satisfying appropriate regularity conditions of course) can be calculated directly by the expression

$$
E\left[F\left(L_{t}\right)\right]=\sum_{i=0}^{\infty} \sum_{j=0}^{\infty} \sum_{k=0}^{\infty} \frac{P_{1, i}\left(\lambda_{1}, t\right)}{i !} \frac{P_{2, j}\left(\lambda_{2}, t\right)}{j !} \frac{P_{3, k}\left(\lambda_{3}, t\right)}{k !} F\left(L_{t}\right) .
$$

Although the summations range from zero to infinity, only the first few terms generally need to be evaluated since the remainder are negligible.

\section{VALUING TRANCHES}

Given the solutions for the Poisson probabilities and the equation above, it is now straightforward to value securities with cash flows tied to the realized credit losses of an underlying portfolio such as the CDX index. In practice, cash flows for the CDX index and its tranches occur discretely (typically on a quarterly frequency) and these contracts can be valued by applying Equation (15) to each discounted cash flow and then summing over all cash flows. To build intuition about these contracts, however, this section provides formal expressions for the values of the CDX index spread and the spreads on its tranches using the convenient assumption that cash flows are paid continuously. Observe, however, that these formal expressions are simply illustrative; the empirical results presented in the paper are based on the actual discrete cash flows and are valued using Equation (15) to evaluate expectations under the risk-neutral measure.

Let $D(t)$ denote the present value (as of time zero) of a zero-coupon riskless bond with a maturity date of $t$. Turning first to the CDX index, recall that a protection buyer pays a fixed annuity of $c$ on the remaining balance of the CDX portfolio in

exchange for protection against default losses as they occur. Thus, the value of the premium leg can be expressed as 


$$
c E\left[\int_{0}^{T}\left(1-L_{t}\right) e^{-\left(\int_{0}^{t} r_{s} d s\right)} d t\right]
$$

This expression reflects that the fixed annuity is received continuously on the remaining notional amount of the index, $1-L_{t}$. The exponential term in the integral is the discount factor applied to the fixed annuity payments. For simplicity, we will assume that the riskless interest rate is independent of the Poisson and intensity processes. Similarly, the value of the protection leg is given by

$$
E\left[\int_{0}^{T} e^{-\left(\int_{0}^{t} r_{s} d s\right)} d L\right]
$$

where $d L$ represents the change in the total cumulative losses on the portfolio, which is just the instantaneous realized loss. Since $L_{t}$ is a nondecreasing process, the integral in the above equation represents a standard Riemann-Stieltjes integral. The Appendix provides a closed-form solution for the value of $c$ implied by the two expressions above.

As an aside, we note that a much more convenient expression for the value of $c$ can be obtained by slightly modifying the definition of the cash flows received from the CDX index. Specifically, by assuming that the cash flows from both legs of the CDX contract are paid on the unamortized balance (rather than the amortized balance), the value of $c$ can be expressed as

$$
c=\frac{\int_{0}^{T} D(t)\left(\bar{\gamma}_{1} E\left[\lambda_{1 t}\right]+\bar{\gamma}_{2} E\left[\lambda_{2 t}\right]+\bar{\gamma}_{3} E\left[\lambda_{3 t}\right]\right) d t}{\int_{0}^{T} D(t) d t} .
$$

where the expected value of an intensity process is given by

$$
E\left[\lambda_{t}\right]=e^{-\beta t} \lambda+\left(\frac{\alpha}{\beta}\right)\left(1-e^{-\beta t}\right) .
$$

Since the same amortization is applied to both legs on the contract, this simplification has very little effect on the value of $c$. In the special case where the intensity processes follow martingales $(\alpha=\beta=0)$, Equation (18) reduces further to give

$$
c=\bar{\gamma}_{1} \lambda_{1}+\bar{\gamma}_{2} \lambda_{2}+\bar{\gamma}_{3} \lambda_{3}
$$

Thus, the CDX index spread becomes a simple linear combination of the current jump intensities for the three Poisson processes in this special case. 
Turning now to the valuation of tranches, we observe that the total losses on an individual $N-M$ percent tranche can be modeled as a call spread on the underlying state variable $L_{t}$. Specifically, the total losses $V_{t}$ on a $N-M$ tranche can be expressed as

$$
V_{t}=\frac{1}{M-N}\left(\max \left(0, L_{t}-N\right)-\max \left(0, L_{t}-M\right)\right)
$$

where $N$ and $M$ are denoted in decimal form. This expression reflects that if the total loss on the underlying portfolio $L_{t}$ is less than $N$, then the loss on the tranche $V_{t}$ is zero. If $L_{t}$ is midway between $N$ and $M$, the total loss on the tranche $V_{t}$ is 0.50 or 50 percent. If $L_{t}$ equals or exceeds $M$, the total loss on the tranche $V_{t}$ equals 1.00 or 100 percent. As with the total losses on the underlying portfolio, $V_{t}$ is a nondecreasing function of time.

As with the index, an investor in a index tranche receives a fixed annuity of $h$ on the remaining balance $1-V_{t}$ of the tranche, in exchange for compensating the protection buyer for the losses $d V$ on the tranche. Thus, the value of the premium leg of a $N-M$ percent tranche is given formally by,

$$
h E\left[\int_{0}^{T}\left(1-V_{t}\right) e^{-\left(\int_{0}^{t} r_{s} d s\right)} d t\right]
$$

Similarly, the value of the protection leg of the $N-M$ percent tranche is given by

$$
E\left[\int_{0}^{T} e^{-\left(\int_{0}^{T} r_{s} d s\right)} d V\right]
$$

where this integral is once again a Riemann-Stieltjes integral. Setting the value of the two legs equal to each other and solving for the value of the tranche spread $h$ gives,

$$
h=\frac{\int_{0}^{T} D(t) E[d V]}{\int_{0}^{T}\left(1-E\left[V_{t}\right]\right) D(t) d t} .
$$

The expectation $E\left[V_{t}\right]$ in this expression is easily evaluated by substituting the closedform solutions for the Poisson probabilities into Equation (15). Although $d V$ is itself expressible as a linear combination of call options on $L_{t}$, it is generally much more convenient to evaluate $E[d V]$ numerically by solving for the difference between $E\left[V_{t+\epsilon}\right]$ and $E\left[V_{t}\right]$ for some suitably small value of $\epsilon$. 


\section{EMPIRICAL ANALYSIS}

In this section, we estimate the model using the times series of CDX index values and the associated index tranche prices. We then examine how the model performs and explore the economic implications of the results.

\subsection{The Empirical Approach.}

To make the intuition behind the results more clear, we focus on the simplest specification of the model in which each of the intensity processes follows a martingale. Thus, we assume that the $\alpha$ and $\beta$ parameters in Equations (3) through (5) are zero. As we will show, even this simplified specification provides strikingly good results.

In this specification, there are six parameters that need to be estimated: the three jump size parameters $\gamma_{1}, \gamma_{2}$, and $\gamma_{3}$, and the three volatility parameters $\sigma_{1}, \sigma_{2}$, and $\sigma_{3}$. In addition, the values of the three intensity processes need to be estimated for each date. Our approach in estimating the model will be to solve for the parameter and intensity values that best fit the model to the data. In doing this, we estimate the model separately for each of the five CDX indexes. The reason for this is that there are slight differences in the composition of the individual indexes, potentially resulting in minor differences in parameter values.

Let us illustrate the estimation approach with the specific example of the CDX 1 index. The CDX 1 index was the on-the-run index from October 20, 2003 to March 20,2004 , and there are 65 observations for this index in the data set. To estimate the model, the algorithm first picks a trial set of values for the six $\gamma$ and $\sigma$ parameters. Then for each of the 65 days in the sample period (and conditional on the parameter values), we solve for the three values of the intensity process in the following way. First, we require that the values of the intensity processes fit exactly the market value of the CDX index spread. The other identification conditions are provided by requiring that the values of the intensity processes minimize the sum of squared errors between the market and model-implied tranche spreads for the $0-3,3-7,7-10,10-15$, and 15-30 percent tranches. Thus, we are using six market prices (the index and five tranche spreads) to identify the three intensity processes for each date (conditional on the parameter values). Once we have estimated the values of the three intensity processes for each of the 65 days, we then evaluate the sum of squared errors for the five tranches over all 65 days. Finally, we iterate the process over different sets of parameter values until we find a single set of parameter values that minimizes the sum of squared errors over all 65 days in the sample period, given that the intensity values are chosen to match the CDX index exactly and minimize the sum of squared errors for the five tranches on each date. This algorithm is essentially nonlinear least squares and has been widely used in the finance literature in similar types of applications. ${ }^{6}$

${ }^{6}$ See Longstaff, Mithal, and Neis (2005), Liu, Longstaff, and Mandell (2006), and many others. 
We use a similar procedure to estimate the model for the other CDX indexes.

It is important to note that estimated parameter values and intensities are relative to the risk-neutral pricing measure. A more general analysis might be to follow an approach such as Duffie and Singleton (1997) or Pan and Singleton (2005) in which both the risk-neutral parameters and market prices of risk are estimated by maximum likelihood. To estimate these market prices of risk accurately, however, one would likely need to have more than just the two years of data available to us given the wellknown difficulty in estimating the drift of a diffusion process (and, therefore, market prices of risk). Accordingly, we limit our analysis to the estimation of parameters and intensity processes under the pricing or risk-neutral measure.

\subsection{Testing for the Number of Factors.}

One of the fundamental issues that needs to addressed at the outset is the question of how many factors are actually needed in pricing CDOs. So far, we have presented a three-factor version of the model. Clearly, however, the model could be adapted to allow only one or two factors by simply setting the values of two or one of the intensity processes to zero. ${ }^{7}$ In this section, we explore the issue of how many factors are needed by testing whether the two-factor version has incremental explanatory power relative to the one-factor version, and then whether the three-factor version has incremental explanatory power relative to the two-factor version. The testing methodology is based on straightforward chi-square tests of difference in the log sum of squared pricing errors.

These tests for the number of factors needed to price tranches also provide insight into an issue that is of fundamental importance in credit markets - default correlation. To see this, imagine the hypothetical situation where defaults are purely idiosyncratic and independent of each other. Furthermore, assume that the value of the intensity process for each firm in the CDX is a constant 0.01, and that the default of any firm results in a loss of $1 / 125$ of the value of the portfolio (equal weights). Recall that the sum of independent Poisson realizations is itself a Poisson random variate with intensity equal to the sum of the intensities of the individual independent Poisson processes. In this independent default case, the total losses on the portfolio could be modeled as the realization of a single Poisson process with intensity of $125 \times 0.01=1.25$, and where each event results in a jump of $1 / 125$. This means that only one factor would be needed to capture CDO pricing if defaults were in fact independent. On the other hand, if defaults are not independent and some correlation or clustering in default occurs, it would no longer be possible to represent total portfolio losses as the realization of a single Poisson event. Rather, we would expect to find that more than one Poisson process is needed to explain the cross section of tranche spreads across different attachment points. Thus, finding that a one-factor model is not sufficient to explain

${ }^{7}$ Similarly, the model could be extended to allow for four (or even more) factors by adding an intensity process in the obvious way. 
CDO pricing would represent direct evidence that the market expects correlation or clustering in the defaults of CDX firms.

Table 3 presents summary statistics for the pricing errors obtained by estimating one-factor, two-factor, and three-factor versions of the model. In each case, the values of the intensity processes are chosen to match the CDX index spread exactly. In the two-factor and three-factor models, the RMSE of the difference between market and model implied spreads for the five index tranches is also minimized. The table reports the RMSEs for each of the $0-3,3-7,7-10,10-15$, and $15-30$ percent tranches individually, as well as the overall RMSE over all tranches. Table 3 also reports the $p$-values for the chi-square tests of the two-factor vs. one-factor and three-factor vs. two-factor specifications. In the one-factor specification, we estimate the two parameters $\gamma_{1}$ and $\sigma_{1}$, as well as $N$ values of $\lambda_{1}$, where $N$ is the number of days in the sample. In the two-factor specification, we estimate the four parameters $\gamma_{1}, \gamma_{2}$, $\sigma_{1}$, and $\sigma_{2}$ as well as $N$ values each for $\lambda_{1}$ and $\lambda_{2}$. Thus, the one-factor specification is nested within the two-factor specification by imposing $N+2$ restrictions; the chisquare statistic has $N+2$ degrees of freedom. Similarly for the test of the three-factor vs. two-factor specification.

As shown in Table 3, the RMSEs for the one-factor version of the model are very large across all of the tranches. The overall RMSEs range from about 30 to 41 basis points. Increasing the number of factors to two results in a significant reduction in the RMSEs, both overall and across tranches. Typically, the overall RMSE for the two-factor version of the model is between about 5 and 14 basis points. For each CDX index, the incremental explanatory power of the two-factor version relative to the one-factor version is highly statistically significant.

The three-factor version of the model results in very small RMSEs. With the exception of the CDX 1 index, the overall RMSEs are all on the order of two to three basis points. In fact, the RMSE for CDX 5 is actually less than one basis point. Again, with the exception of the CDX 1 index, the incremental explanatory power of the three-factor version relative to the two-factor model is highly significant. Thus, the three-factor model provides a very close fit to the data. Accordingly, we will report results based on the three-factor version of the model throughout the remainder of the paper.

\subsection{The Parameter Estimates.}

Table 4 reports the parameter estimates obtained from the three-factor model. Focusing first on the estimates of the jump sizes, Table 4 shows that there is a strong uniformity across the different CDX indexes. In particular, the jump sizes associated with the first Poisson process are in a tight range from 0.00387 to 0.00469 . Since each firm in the CDX index has a weight of $1 / 125=0.008$ in the index, a jump size of, say, 0.004 is completely consistent with the interpretation that a jump in the first Poisson process represents the idiosyncratic default of an individual firm, where the implicit 
recovery rate for the firm's debt is 50 percent. If we adopt this interpretation, then the implied recovery rates implied by the estimated jump sizes are 56.6, 51.4, 50.3, 48.4, and 58.6 percent for the individual CDX indexes, respectively.

The jump sizes for the second Poisson process are also very uniform across the CDX indexes, ranging from roughly 0.052 to 0.066 . These values are consistent with the interpretation of the second Poisson process reflecting a major event in a specific sector or industry. As one way of seeing this, observe that virtually every broad industry classification is represented in the CDX index. In particular, the CDX index includes firms in the consumer durables, nondurables, manufacturing, energy, chemicals, business equipment, telecommunications, wholesale and retail, finance and insurance, health care, utilities, and construction industries. If we place the CDX firms into these 12 broad industry categories, then this implies that there are 125/12 $=10.42$ firms per category. Assuming a 50 percent recovery rate, a major event that resulted in the loss of an entire industry would lead to a total loss for the index of $10.42 / 125 \times 0.50=0.042$, which is on the order of magnitude of the jump size estimated for the second Poisson process.

The estimated jump sizes for the third Poisson process display somewhat more variation than for the other two Poisson processes, with values ranging from about 0.17 to 0.52 . The average value across all five indexes is about 0.35. Again assuming a 50 percent recovery rate, a jump size of 0.35 associated with a realization of the third Poisson process can be given the interpretation as a major economic shock to the entire economy in which as many as 70 percent of all firms default of their debt. This is clearly a nightmare scenario that is difficult to imagine occuring. Potential examples of such a scenario might include nuclear war, a worldwide pandemic, or a severe and sustained economic depression. We note that the latter would need to be much more severe than any the U.S. has yet experienced.

Turning now to the estimates of the volatility parameters, Table 4 shows that the volatility estimates of each of the three intensity processes are generally of the same order of magnitude. Specifically, with the exception of the first CDX index, the volatility parameters range from roughly 0.10 to 0.30 across all three processes and across all the CDX indexes. Recall from Equation (20) that the CDX index spread can be approximated as a linear combination of the three intensity processes. Thus, the volatility of the CDX index spread could be related to these volatility parameters. The results in Table 4 indicate that the volatilities of the intensity processes, or equivalently, the volatilities of the CDX index and tranche spreads, are important determinants of market CDO prices.

\subsection{The Intensity Processes.}

Fig. 3 plots the time series of the estimated values of the three intensity processes. Table 5 presents summary statistics for these estimated values.

As shown, the first intensity process $\lambda_{1}$ ranges from roughly 0.50 to 1.50 during 
the sample period. For the majority of the sample period, this process takes values between 0.60 to 0.90 and displays a high level of stability. During the credit crisis of May 2005, however, this intensity process spiked rapidly to a value of 1.517 , but then declined to just over 1.00 by the middle of June 2005. Thus, this spike was relatively short lived. Given the average value of $\lambda_{1}$ during the sample period, the expected waiting time until a firm-specific default is 1.16 years.

The second intensity process $\lambda_{2}$ ranges from a high of about 0.04 to a low of about 0.01 during the sample period. The value of this process is generally declining throughout the period. During the credit crisis, the value of this process doubled from about 0.015 to just over 0.030 . After the crisis, the value of this process continued to decline. This suggests that the market implied probability of a major industry or sector crisis declined significantly during the past several years. Put another way, the expected waiting time for this type of event declined from roughly 28 years to 125 years during the sample period. The average waiting time for a realization of the second Poisson process is 41.5 years during the sample period.

The third intensity process $\lambda_{3}$ has more apparent variability across CDX indexes than do the other two intensity processes. In particular, the value of this process increases rapidly for the CDX 1 index, but then generally takes lower values for the other four CDX indexes. As with the second intensity process, the third intensity process essentially doubles around the time of the credit crisis. The average value for this intensity process throughout the entire sample period is 0.00131 . Thus, the implied risk-neutral probability of a catastrophic meltdown scenario is very small with an expected waiting time of about 763 years on average.

\subsection{Index Spread Components.}

There are several ways in which the marginal impact of each type of default risk on the overall CDX index spread can be evaluated, each of which gives very similar results. One particularly intuitive way of doing this is simply to adopt the slightly modified definition of CDX index contract cash flows discussed in Section 5. Recall that this implies that the CDX index spread can be expressed as a linear combination of the three intensity processes. Thus, we can decompose the CDX index spread into three distinct components to measure the approximate overall economic impact of idiosyncratic, industry, and economywide default risks. In particular, the idiosyncratic component of the CDX index spread is given by $\bar{\gamma}_{1} \lambda_{1}$, the industry component is given by $\bar{\gamma}_{2} \lambda_{2}$, and the economywide component is given by $\bar{\gamma}_{3} \lambda_{3}$. Recall from Equation (20) that the sum of these three components approximates the value of the CDX index spread.

Table 6 reports summary statistics for these three components. As shown, idiosyncratic default risk accounts for about two-thirds of the total value of the CDX index spread across the different indexes. Interestingly, however, the percentage of the CDX index spread due to idiosyncratic default risk has increased steadily throughout 
the sample period. In particular, the percentage has increased from about 58 percent for the first two indexes to more than 82 percent for the CDX 5 index.

The portion of the CDX index spread due to industry or sector default risk declined significantly during the sample period. In particular, the portion due to industry default risk is about 33 percent for the CDX 1 index, but only about 10 percent for the CDX 5 index. This decline reflects the dramatic decrease in the value of the second intensity process $\lambda_{2 t}$ during the sample period.

Economywide default risk accounts for an average of about 7 to 12 percent of the total CDX index value. There is no clear trend in the size of this component during the sample period. We note, however, that this component takes its largest value for the CDX 4 index which spans the period during the May 2005 credit crisis.

In summary, these results indicate that idiosyncratic default risk constitutes the majority of the CDX index spread. The combined effects of industry and economywide risk, however, are also significant and have represented more than 40 percent of the total CDX index spread. Even though the probabilities of industrywide or catastrophic economywide default events are much smaller than the probability of an isolated idiosyncratic default, the economic impact of these types of events is much more severe. Thus, industry and economywide default risks have a disproportionately larger influence on the value of the overall CDX index.

Since the CDX index spread is an average of the default spreads for the underlying 125 firms in the index, the decomposition of the index into the three types of default events is equally applicable to the typical firm in the index. Thus, our results imply that the event of default for the typical firm can be partitioned into three mutually exclusive events: the event that only the firm defaults, the event that the firm and many of the other firms in its industry or sector default together, and the event that the firm and the majority of all firms in the economy default. On average, the probabilities of the three types of default events are 64.6, 27.1, and 8.3 percent, respectively, of the total default probability for the typical firm in the index.

\subsection{The Time Series of RMSEs.}

Although Table 3 reports summary RMSE statistics for the three-factor model, it is also interesting to examine the time series variation in the ability of the model to capture market tranche spreads more closely. Accordingly, Figure 4 plots the time series of daily RMSEs obtained by fitting the model to the five tranches.

As shown, the ability of the model to match market tranche spreads increased significantly during the sample period. Initially, some of the RMSEs are as large as 19 basis points. The RMSEs decline rapidly, however, and are on the order of five basis points by early 2004. By mid 2004, the RMSEs decline further and hover around two basis points for most of the sample period. The only exception is around the May 2005 credit crisis when the RMSE increases slightly to about five basis points. After the crisis, however, the RMSEs decline rapidly and reach values below one basis point near 
the end of the sample period. The small spikes in the RMSEs at the beginning and end of each index series are potentially due to the effects of investors rolling positions from tranches based on the previous index to tranches based on the new on-the-run index.

These results provide evidence consistent with the view that while the fledging index tranche market may have experienced some inconsistencies in the relative pricing of individual tranches, the market matured rapidly and pricing errors were quickly arbitraged away. In fact, this market now appears to be very consistent in terms of the relative pricing of tranches. In particular, the fact that the RMSEs increased to only about five basis points during the credit crisis of May 2005 makes a strong case that the model captures the underlying economics of the market.

\subsection{Pricing Errors.}

We turn next to the pricing errors, defined as the difference between the model implied spreads and the market spreads for the various CDX index tranches, and examine their properties. Figure 5 plots the pricing errors for the various tranches. Table 7 presents summary statistics and reports $t$-statistics for the significance of the average pricing errors.

As shown, the pricing errors from the three factor model are surprisingly small across all indexes and tranches. In particular, the average pricing errors are all within 10 basis points of zero and most are within one or two basis points of zero. Recall from Table 1 that the average sizes for the $0-3,3-7,7-10,10-15$, and $15-30$ percent tranche spreads are about 1759, 240, 82, 34, and 12 basis points, respectively. Thus, average pricing errors of only a few basis points are extremely small in percentage terms as well.

The pricing errors for the equity $0-3$ percent tranches are particularly small. With the exception of the CDX 1 index, the average pricing errors for the equity tranche are all within 1.5 basis points of zero. Pricing errors this small would clearly be well within the bid-ask spread for these securities. Even the average pricing error of -7 basis points for the CDX 1 index is well within one percent of the average size of the $0-3$ percent tranche spread.

The pricing errors for the junior mezzanine 3-7 percent tranche are uniformly small across all the indexes. In most cases, the average pricing errors are inside of a single basis point. Again, this is remarkably small in terms of the average size of the spreads for this tranche. The pricing errors for the mezzanine $7-10$ percent tranche are the smallest of all of the tranches. The pricing errors for the senior 10-15 percent tranche are also generally small. For the CDX 3, 4, and 5 indexes, the average pricing errors for this tranche are all less than one basis point in magnitude.

Finally, the pricing errors for the senior 15-30 percent tranche are also generally small. Since the average spread on this tranche is only about 12 basis points, however, the percentage pricing errors on this tranche are probably the largest among all of the 
tranches. Despite this, these average pricing errors are generally well within the two to three basis points bid-ask spread for this tranche observed in the market.

Table 7 also reports the $t$-statistics for the mean (correcting for the persistence in the pricing errors). As shown, the only statistically significant mean pricing errors occur for the CDX 1 index. Specifically, the pricing errors for the $0-3$ percent equity and 15-30 percent senior tranches have significant means for the CDX 1 index. Thus, these results are consistent with the interpretation that there may have been arbitrage opportunities across CDX tranches during the early stages of the market. As shown in Figure 5, however, these pricing errors dissipated rapidly and were largely gone by the beginning of 2004 .

\subsection{Spread Dispersion.}

Industry sources often suggest that there is a relation between CDO pricing and the dispersion of CDS levels of the individual firms within the index. Intuitively, the idea is that market tranche spreads should differ between the case where all 125 firms in the CDX index have a CDS spread of 100 basis points and the case where half of the firms have a spread of 50 basis points and half have a spread of 150 basis points (one firm with a spread of 100 basis points), even though in both cases, the CDX index spread would be 100 basis points. Intuitively, the substance of the dispersion argument is that the CDX index spread is not a sufficient state variable for pricing tranches, a claim that is consistent with our evidence that multiple factors affect the pricing of CDX index tranches.

To explore whether dispersion in the CDS levels of the individual firms affects the pricing of CDOs we do the following. First, for each date in the sample period, we solve for the standard deviation of the loss distribution implied by the fitted model at the five-year horizon. Second, we regress the implied standard deviation of the loss distribution on the level of the CDX and the dispersion of individual CDS levels. The dispersion measure is given by the cross-sectional standard deviation of CDS levels for the 125 individual firms in the CDX index. ${ }^{8}$ The intuition behind this test approach is that since the mean of the loss distribution tends to be almost completely determined by the CDX level, any effects of dispersion would likely show up in the second and/or higher moments of the loss distribution. Finding that the dispersion measure has significant explanatory power would provide evidence that dispersion affects the relative pricing of CDX index tranches and that the effects of dispersion are captured within the model.

Table 8 reports the results from the regression. As shown, both the CDX index spread and the dispersion measure have significant explanatory power for the implied standard deviation of the loss distribution. The sign of the coefficient for the dispersion

${ }^{8}$ The data for the individual CDS levels in the CDX indexes are also provided by Citigroup. 
measure is positive, indicating that greater dispersion or heterogeneity in CDS levels tends to increase the volatility of the loss distribution.

These results can be viewed as additional evidence against the hypothesis that defaults are uncorrelated. Specifically, if defaults were uncorrelated, then the losses for the CDX portfolio could be modeled based on the realizations of a single Poisson process. Recall that the first and second moments of an individual Poisson process are equal. Thus, if defaults were uncorrelated, then the second moment of the loss distribution would be completely determined by its first moment, or equivalently, by the CDX index spread.

\section{CONCLUSION}

This paper conducts an in-depth empirical analysis of the pricing of synthetic CDX index tranches in the financial markets. Motivated by the Duffie and Gârleanu (2001) multifactor framework, we develop a new portfolio credit model in which three types of Poisson events generate portfolio credit losses. Using an extensive data set of CDX index and tranche spreads, we estimate the model and evaluate its performance.

A number of interesting results emerge from this analysis. For example, we find that one-factor and even two-factor models are insufficient to explain the relative pricing of CDX index tranches in the market. In contrast, a three-factor model that allows for jumps of approximate sizes $0.004,0.06$, and 0.35 explains virtually all of the cross-sectional and time-series variation in the index tranche data. Assuming a 50 percent recovery rate, a jump of 0.004 has the clear interpretation of an idiosyncratic default of a single firm out of the 125 firms in the CDX index $(0.50 \times 1 / 125=0.004)$. Similarly, a jump size of 0.06 has the interpretation of a default event in which roughly 10 percent of the firms in the index default together. This could be viewed as an event in which an entire industry or sector experiences financial distress. Finally, a jump size of 0.35 represents the realization of a financial catastrophe in which more than 50 percent of the firms in the economy default on their debt. The results indicate that under the risk-neutral measure, the average expected time until a realization of these three types of events is $1.2,41.5$, and 763 years, respectively.

The results provide a number of insights into the important issue of default clustering. In particular, we find that the market expects significant clustering to occur. Our results allow us to partition the event that a firm defaults into three distinct events: the event that only the firm defaults, the event that the firm and others in its industry or sector default together, and the catastrophic event that the firm along with more than 50 percent of the other firms in the economy default together. We show that roughly one-third of the value of the default spread for the typical firm in the CDX index is due to events in which multiple firms default together.

This paper is only a first attempt to understand how the market prices CDX index 
tranches. The results, however, strongly suggest that the pricing in these markets is highly efficient. This true even during the credit crisis of May 2005 which resulted in major losses for a number of major credit-oriented hedge funds. Furthermore, these results indicate that modeling credit losses at a portfolio level-rather than at an individual firm level and then aggregating up - provides an accurate, tractable, and computationally efficient framework for valuing credit derivatives when the cash flows are based on portfolio credit losses. 


\section{APPENDIX}

There are several ways in which the partial differential equation for $P_{i}$ can be derived. For example, the approach outlined in Karlin and Taylor (1981) pp. 202-204 leads directly to the partial differential equation. To provide an alternative approach, recall that

$$
P_{i}=E_{t}\left[\exp \left(-\int_{0}^{T} \lambda_{s} d s\right)\left(\int_{0}^{T} \lambda_{s} d s\right)^{i}\right]
$$

Let

$$
H_{t}=\int_{0}^{t} \lambda_{s} d s
$$

This implies

$$
d H_{t}=\lambda_{t} d t
$$

Now, rewrite $P_{i}$ as

$$
\begin{gathered}
P_{i}=E_{t}\left[\exp \left(-\int_{0}^{t} \lambda_{s} d s-\int_{t}^{T} \lambda_{s} d s\right)\left(\int_{0}^{t} \lambda_{s} d s+\int_{t}^{T} \lambda_{s} d s\right)^{i}\right], \\
=E_{t}\left[\exp \left(-H_{t}-\int_{t}^{T} \lambda_{s} d s\right)\left(H_{t}+\int_{t}^{T} \lambda_{s} d s\right)^{i}\right]
\end{gathered}
$$

From this expression, $P_{i}$ can be expressed explicitly as a function of $\lambda_{t}, H_{t}$, and $\tau=T-t$. An application of Itô's Lemma gives

$$
\begin{gathered}
d P_{i}=(\alpha-\beta \lambda) \frac{\partial P_{i}}{\partial \lambda} d t+\sigma \sqrt{\lambda} \frac{\partial P_{i}}{\partial \lambda} d Z+\frac{\sigma^{2} \lambda}{2} \frac{\partial^{2} P_{i}}{\partial \lambda^{2}} d t \\
-\frac{\partial P_{i}}{\partial \tau} d t-\lambda P_{i} d t+i \lambda P_{i-1} d t
\end{gathered}
$$


Since $P_{i}$ is a martingale, however, the expected value of $d P_{i}=0$. Thus,

$$
\frac{\sigma^{2} \lambda}{2} \frac{\partial^{2} P_{i}}{\partial \lambda^{2}}+(\alpha-\beta \lambda) \frac{\partial P_{i}}{\partial \lambda}-\lambda P_{i}+i \lambda_{t} P_{i-1}=\frac{\partial P_{i}}{\partial \tau},
$$

which is Equation (8) (at $t=0$ ). For $i=0$, the boundary condition is $P_{0}(\lambda, 0)=1$. For all other $i$, the boundary condition is $P_{i}(\lambda, 0)=0$.

For the case $i=0$, the solution to the partial differential equation is identical to that provided by Cox, Ingersoll, and Ross (1985) in obtaining zero-coupon bond prices. The solution for this case can be expressed as shown in Equation (9) with $i=0$. For $i>0$, we conjecture that the solution is of the form shown in Equation (9). Differentiating the conjectured solution for $P_{i}(\lambda, T)$, substituting into Equation (10), and collecting terms in the powers of $\lambda$ leads to the system of first-order differential equations shown in Equations (12), (13), and (14). This system can be solved recursively following in the order $C_{1,1}, C_{1,0}, C_{2,2}, C_{2,1}, C_{2,0}, C_{3,3}, C_{3,2}, C_{3,1}, C_{3,0}$, etc. Thus, for each $i$, we solve for $C_{i, j}$, where $j$ runs backwards from $i$ to 0 .

Turning now to the derivation of the CDX index value in Section 5, we observe that conditional on the path of the intensity process, the expectation of $\exp \left(-\gamma N_{t}\right)$ is

$$
E\left[e^{-\gamma N_{t}} \mid \cdot\right]=\exp \left(-\bar{\gamma} \int_{0}^{t} \lambda_{s} d s\right),
$$

This follows from the definition of the moment generating function for Poisson variates. Similarly, the conditional expectation of $d N_{t}$ is $\lambda_{t} d t$. Since $N_{t}$ and $d N_{t}$ are conditionally independent (but not unconditionally), the conditional expected value of terms involving the product $e^{-\gamma N_{t}} d N_{t}$ is simply the product of these two conditional expectations. From Equation (A8), one minus the expected loss conditional on the paths of the intensity processes is given by

$$
1-E\left[L_{t} \mid \cdot\right]=\exp \left(-\int_{0}^{t} \bar{\gamma}_{1} \lambda_{1 s}+\bar{\gamma}_{2} \lambda_{2 s}+\bar{\gamma}_{3} \lambda_{3 s} d s\right) .
$$

Using the results above in conjunction with Equations (16) and (17) implies that the CDX index spread can be expressed formally as 


$$
c=\frac{\int_{0}^{T} D(t) E\left[\exp \left(-\int_{0}^{t} \bar{\gamma}_{1} \lambda_{1 s} d s+\bar{\gamma}_{2} \lambda_{2 s} d s+\bar{\gamma}_{3} \lambda_{3 s} d s\right)\left(\bar{\gamma}_{1} \lambda_{1 t}+\bar{\gamma}_{2} \lambda_{2 t}+\bar{\gamma}_{3} \lambda_{3 t}\right)\right] d t}{\int_{0}^{T} D(t)\left(1-E\left[L_{t}\right]\right) d t} .
$$

To evaluate this expression, we need to provide solutions for the unconditional moments that appear in the numerator and denominator. The unconditional expectation for the portfolio loss $E\left[L_{t}\right]$ is

$$
E\left[L_{t}\right]=1-E\left[e^{-\gamma_{1} N_{1 t}}\right] E\left[e^{-\gamma_{2} N_{2 t}}\right] E\left[e^{-\gamma_{3} N_{3 t}}\right],
$$

where

$$
E\left[e^{-\gamma N_{t}}\right]=E\left[\exp \left(-\bar{\gamma} \int_{0}^{t} \lambda_{s} d s\right)\right]=\hat{A}(t) e^{-\hat{B}(t) \lambda}
$$

and where $\hat{A}(t)$ and $\hat{B}(t)$ are the same as in Equations (10) and (11) except that $\xi$ is replaced by the constant $\sqrt{\beta^{2}+2 \sigma^{2}} \bar{\gamma}$. This result is obtained by a simple extension of the approach used in Cox, Ingersoll, and Ross (1985) in valuing zero-coupon bonds. These results imply that

$$
1-E\left[L_{t}\right]=\hat{A}_{1}(t) \hat{A}_{2}(t) \hat{A}_{3}(t) \exp \left(-\hat{B}_{1}(t) \lambda_{1}-\hat{B}_{2}(t) \lambda_{2}-\hat{B}_{3}(t) \lambda_{3}\right),
$$

where the subscripted values of $\hat{A}(t)$ and $\hat{B}(t)$ correspond to the respective Poisson processes in the obvious way.

Multiplying out the expression in the numerator of Equation (A10) leads to products of terms of the form given in Equation (A12) and also terms of the form,

$$
E\left[\exp \left(-\hat{\gamma} \int_{0}^{t} \lambda_{s} d s\right) \lambda_{t}\right]
$$

These latter expectations, however, can be evaluated directly from the results in Duffie, Pan, and Singleton (2000). Specifically, the expectation in Equation (A14) has the form $\tilde{A}(t) \exp (-\hat{B}(t) \lambda)(1+\tilde{C}(t))$ where $\hat{B}(t)$ is as defined above in Equation (A12), $\tilde{C}(t)$ is the solution to the following ordinary differential equation, 


$$
\frac{d \tilde{C}}{d t}=-\left(\sigma^{2} \hat{B}(t)+\beta\right) \tilde{C}(t)-\alpha \tilde{C}(t)^{2}
$$

with boundary condition $\tilde{C}(0)=1$, and $\tilde{A}(t)$ is given as

$$
\ln (\tilde{A}(t))=\alpha \int \tilde{C}(s)-\hat{B}(s) d s
$$

with boundary condition $\tilde{A}(0)=1$. From the expressions for these unconditional expectations in Equations (A12) and (A14), we can then solve for the unconditional expectation in the numerator of Equation (A10). Specifically, this expectation is given by

$$
\begin{aligned}
& \bar{\gamma}_{1} \tilde{A}_{1}(t) e^{-\hat{B}_{1}(t) \lambda_{1}}\left(1+\tilde{C}_{1}(t)\right) \hat{A}_{2}(t) e^{-\hat{B}_{2}(t) \lambda_{2}} \hat{A}_{3}(t) e^{-\hat{B}_{3}(t) \lambda_{3}} \\
+ & \bar{\gamma}_{2} \hat{A}_{1}(t) e^{-\hat{B}_{1}(t) \lambda_{1}} \tilde{A}_{2}(t) e^{-\hat{B}_{2}(t) \lambda_{2}}\left(1+\tilde{C}_{2}(t)\right) \hat{A}_{3}(t) e^{-\hat{B}_{3}(t) \lambda_{3}} \\
+ & \bar{\gamma}_{3} \hat{A}_{1}(t) e^{-\hat{B}_{1}(t) \lambda_{1}} \hat{A}_{2}(t) e^{-\hat{B}_{2}(t) \lambda_{2}} \tilde{A}_{3}(t) e^{-\hat{B}_{3}(t) \lambda_{3}}\left(1+\tilde{C}_{3}(t)\right) .
\end{aligned}
$$

Similarly, the expectation in the denominator of Equation (A10) is given from Equation (A13). Substituting these expressions into Equation (A10) gives the closed-form solution for the CDX index spread $c$. 


\section{REFERENCES}

Bakshi, G., D. Madan, and F. Zhang, 2004, Investigating the Role of Systematic and Firm-Specific Factors in Default Risk: Lessons from Empirically Evaluating Credit Risk Models, Journal of Business, forthcoming.

Cox, J., J. Ingersoll, and S. Ross, 1985, A Theory of the Term Structure of Interest Rates, Econometrica 53, 385-407.

Das, S., D. Duffie, N. Kapadia, and L. Saita, 2006, Common Failings: How Corporate Defaults are Correlated, Journal of Finance, forthcoming.

Duffie, D., and N. Gârleanu, 2001, Risk and Valuation of Collateralized Debt Obligations, Financial Analysts Journal 57 (January/February), 41-59.

Duffie, Darrell, Jun Pan, and Kenneth J. Singleton, 2000, Transform analysis and asset pricing for affine jump-diffusions, Econometrica 68, 1343-1376.

Duffie, D., L. Saita, and K. Wang, 2005, Multi-Period Corporate Default Prediction with Stochastic Covariates, Journal of Financial Economics, forthcoming.

Duffie, Darrell, and Kenneth J. Singleton, 1997, An econometric model of the term structure of Interest-Rate Swap yields, Journal of Finance 52, 1287-1321.

Duffie, D., and K. Singleton, 1999, Modeling Term Structures of Defaultable Bonds, Review of Financial Studies 12, 687-720.

Duffie, D., and K. Singleton, 2003, Credit Risk: Pricing, Measurement, and Management, (Princeton University Press, Princeton, NJ).

Jorion, P., and G. Zhang, 2005, Intra-Industry Credit Contagion: Evidence from Credit Default Swap and Equity Markets, Working Paper, University of California at Irvine.

Karlin, S., and H. Taylor, 1981, A Second Course in Stochastic Processes, Academic Press Inc, Orlando, Florida.

Li, D., R. Roy, and J. Skarabot, 2004, A Primer on Single-Tranche CDOs, Citigroup Global Structured Credit Research, Citigroup, New York, NY.

Liu, J., F. Longstaff, and R. Mandell, 2006, The Journal of Business, forthcoming.

Longstaff, F., S. Mithal, and E. Neis, 2005, Corporate Yield Spreads: Default Risk or Liquidity? New Evidence from the Credit Default Swap Market, Journal of Finance 60, 2213-2253.

Marshall, A., and I. Olkin, 1967, A Multivariate Exponential Distribution, Journal 
of the American Statistical Association 62, 30-44.

Pan, J., and K. Singleton, 2005, Default and Recovery Implicit in the Term Structure of Sovereign CDS Spreads, Working Paper, Stanford University.

Roy, R., and D. Shelton, 2004, Trading Credit Tranches, Citigroup Global Structure Credit Research, Citigroup, New York, New York.

Saita, L., 2005, The Puzzling Price of Corporate Default Risk, Working Paper, Stanford University.

Yu, F., 2005a, Correlated Defaults in Intensity-Based Models, Mathematical Finance, forthcoming.

Yu, F., 2005b, Default Correlation in a Reduced-Form Model, Journal of Investment Management 3(4), 33-42. 
Table 1

Summary Statistics for the CDX North American Investment Grade Index and Index Tranches. This table reports summary statistics for the market spreads (measured in basis points) for the indicated time series. Results are reported for the combined on-the-run time series. The sample period is from October 2003 to October 2005.

\begin{tabular}{|c|c|c|c|c|c|c|c|}
\hline & Mean & $\begin{array}{l}\text { Standard } \\
\text { Deviation }\end{array}$ & Minimum & Median & Maximum & $\begin{array}{r}\text { Serial } \\
\text { Correlation }\end{array}$ & $N$ \\
\hline CDX Index & 54.52 & 6.95 & 41.00 & 54.50 & 78.00 & 0.977 & 435 \\
\hline $0-3$ Tranche & 1758.87 & 245.30 & 1282.52 & 1780.28 & 2914.55 & 0.978 & 435 \\
\hline 3-7 Tranche & 240.07 & 85.66 & 103.50 & 232.00 & 411.00 & 0.992 & 435 \\
\hline 7-10 Tranche & 82.27 & 36.73 & 24.75 & 74.75 & 158.00 & 0.992 & 435 \\
\hline 10-15 Tranche & 34.43 & 14.49 & 11.88 & 29.50 & 66.50 & 0.989 & 435 \\
\hline 15-30 Tranche & 11.54 & 2.89 & 5.00 & 11.88 & 20.75 & 0.962 & 435 \\
\hline
\end{tabular}




\section{Table 2}

Correlation Matrix for Daily Changes in Spreads. This table reports the sample correlations for the daily changes in spreads for the indicated time series. Results are reported for the combined on-the-run time series. The sample period is from October 2003 to October 2005.

\begin{tabular}{|c|c|c|c|c|c|c|}
\hline & CDX & $0-3$ & $3-7$ & $7-10$ & $10-15$ & $15-30$ \\
\hline CDX & 1.000 & & & & & \\
\hline $0-3$ & 0.992 & 1.000 & & & & \\
\hline $3-7$ & 0.790 & 0.762 & 1.000 & & & \\
\hline $7-10$ & 0.685 & 0.648 & 0.879 & 1.000 & & \\
\hline $10-15$ & 0.690 & 0.662 & 0.839 & 0.861 & 1.000 & \\
\hline $15-30$ & 0.669 & 0.651 & 0.773 & 0.751 & 0.764 & 1.000 \\
\hline
\end{tabular}


Table 3

Root Mean Squared Errors (RMSE) from Model Fitting and Tests of the Number of Factors. This table reports the overall RMSEs and the RMSEs for the individual CDX index tranches resulting from fitting the indicated models. All RMSEs are measured in basis points. The $p$-value is for the test of $n$ vs. $n-1$ factors. $N$ denotes the number of observations for the indicated CDX index. The sample period is from October 2003 to October 2005.

\begin{tabular}{|c|c|c|c|c|c|c|c|c|c|}
\hline $\begin{array}{l}\text { Number } \\
\text { of Factors }\end{array}$ & Index & \multicolumn{5}{|c|}{ Tranche RMSE } & $\begin{array}{l}\text { Overall } \\
\text { RMSE }\end{array}$ & $p$-Value & $N$ \\
\hline \multirow[t]{5}{*}{ One Factor } & CDX 1 & 13.13 & 78.55 & 17.78 & 40.15 & 13.44 & 41.11 & - & 65 \\
\hline & CDX 2 & 26.90 & 54.02 & 47.08 & 47.50 & 13.37 & 40.73 & - & 108 \\
\hline & CDX 3 & 39.21 & 65.48 & 41.22 & 24.75 & 9.29 & 40.55 & - & 118 \\
\hline & CDX 4 & 31.81 & 39.76 & 47.65 & 23.28 & 12.38 & 33.35 & - & 127 \\
\hline & CDX 5 & 49.58 & 29.92 & 26.37 & 13.83 & 6.21 & 29.25 & - & 17 \\
\hline \multirow[t]{5}{*}{ Two Factors } & CDX 1 & 9.89 & 20.24 & 8.46 & 6.73 & 9.82 & 12.01 & 0.000 & 65 \\
\hline & CDX 2 & 5.60 & 17.17 & 5.12 & 5.89 & 3.02 & 8.90 & 0.000 & 108 \\
\hline & CDX 3 & 3.78 & 5.77 & 3.28 & 1.68 & 3.07 & 4.74 & 0.000 & 118 \\
\hline & CDX 4 & 22.40 & 14.30 & 9.95 & 7.39 & 10.85 & 13.98 & 0.000 & 127 \\
\hline & CDX 5 & 2.24 & 1.95 & 7.13 & 6.99 & 0.66 & 4.67 & 0.000 & 17 \\
\hline \multirow[t]{5}{*}{ Three Factors } & CDX 1 & 11.01 & 4.62 & 8.68 & 10.37 & 8.31 & 8.88 & 0.997 & 65 \\
\hline & CDX 2 & 2.52 & 1.31 & 3.04 & 6.08 & 4.68 & 3.90 & 0.000 & 108 \\
\hline & CDX 3 & 0.99 & 0.76 & 3.36 & 2.80 & 2.06 & 2.23 & 0.000 & 118 \\
\hline & CDX 4 & 1.18 & 1.19 & 4.52 & 2.27 & 2.46 & 2.63 & 0.000 & 127 \\
\hline & CDX 5 & 0.29 & 0.28 & 1.10 & 0.61 & 0.46 & 0.63 & 0.000 & 17 \\
\hline
\end{tabular}


Table 4

Parameter Estimates. This table reports the parameter estimates for the indicated CDX indexes. The sample period is from October 2003 to October 2005

\begin{tabular}{|c|c|c|c|c|c|c|c|}
\hline Index & $\gamma_{1}$ & $\gamma_{2}$ & $\gamma_{3}$ & $\sigma_{1}$ & $\sigma_{2}$ & $\sigma_{3}$ & $N$ \\
\hline $\begin{array}{l}\text { CDX } 1 \\
\text { CDX } 2 \\
\text { CDX } 3 \\
\text { CDX } 4 \\
\text { CDX } 5\end{array}$ & $\begin{array}{c}0.00453 \\
0.00411 \\
0.00402 \\
0.00387 \\
0.00469\end{array}$ & $\begin{array}{l}0.06093 \\
0.06498 \\
0.06621 \\
0.05260 \\
0.05628\end{array}$ & $\begin{array}{l}0.17091 \\
0.35104 \\
0.35347 \\
0.51615 \\
0.33801\end{array}$ & $\begin{array}{l}0.03016 \\
0.20854 \\
0.11955 \\
0.14003 \\
0.17315\end{array}$ & $\begin{array}{l}0.10847 \\
0.19569 \\
0.16863 \\
0.25083 \\
0.27763\end{array}$ & $\begin{array}{c}0.00098 \\
0.14246 \\
0.18110 \\
0.16539 \\
0.29674\end{array}$ & $\begin{array}{r}65 \\
108 \\
118 \\
127 \\
17\end{array}$ \\
\hline
\end{tabular}


Table 5

Summary Statistics for the Estimated Intensity Processes. This table reports summary statistics for the first, second, and third intensity processes for the indicated CDX indexes. Values for the intensity processes represent estimates under the risk-neutral pricing measure. The sample period is from October 2003 to October 2005.

\begin{tabular}{|c|c|c|c|c|c|c|c|}
\hline $\begin{array}{l}\text { Intensity } \\
\text { Process }\end{array}$ & Index & Mean & $\begin{array}{l}\text { Standard } \\
\text { Deviation }\end{array}$ & Minimum & Median & Maximum & $N$ \\
\hline First & $\begin{array}{l}\text { CDX } 1 \\
\text { CDX } 2 \\
\text { CDX } 3 \\
\text { CDX } 4 \\
\text { CDX } 5\end{array}$ & $\begin{array}{l}0.72561 \\
0.85419 \\
0.76570 \\
1.02303 \\
0.81643\end{array}$ & $\begin{array}{l}0.04280 \\
0.02374 \\
0.04105 \\
0.15058 \\
0.02452\end{array}$ & $\begin{array}{l}0.64748 \\
0.79102 \\
0.68886 \\
0.73804 \\
0.79326\end{array}$ & $\begin{array}{l}0.73229 \\
0.85175 \\
0.75330 \\
1.00283 \\
0.81125\end{array}$ & $\begin{array}{l}0.80964 \\
0.90252 \\
0.86144 \\
1.51795 \\
0.86468\end{array}$ & $\begin{array}{r}65 \\
108 \\
118 \\
127 \\
17\end{array}$ \\
\hline Second & $\begin{array}{l}\text { CDX } 1 \\
\text { CDX } 2 \\
\text { CDX } 3 \\
\text { CDX } 4 \\
\text { CDX } 5\end{array}$ & $\begin{array}{l}0.03063 \\
0.03489 \\
0.02115 \\
0.01639 \\
0.00869\end{array}$ & $\begin{array}{l}0.00307 \\
0.00450 \\
0.00411 \\
0.00669 \\
0.00065\end{array}$ & $\begin{array}{l}0.02336 \\
0.02367 \\
0.01464 \\
0.00841 \\
0.00790\end{array}$ & $\begin{array}{l}0.03108 \\
0.03632 \\
0.01999 \\
0.01395 \\
0.00864\end{array}$ & $\begin{array}{l}0.03560 \\
0.04309 \\
0.03077 \\
0.03216 \\
0.00978\end{array}$ & $\begin{array}{r}65 \\
108 \\
118 \\
127 \\
17\end{array}$ \\
\hline Third & $\begin{array}{l}\text { CDX } 1 \\
\text { CDX } 2 \\
\text { CDX } 3 \\
\text { CDX } 4 \\
\text { CDX } 5\end{array}$ & $\begin{array}{l}0.00263 \\
0.00092 \\
0.00093 \\
0.00136 \\
0.00102\end{array}$ & $\begin{array}{l}0.00118 \\
0.00040 \\
0.00013 \\
0.00048 \\
0.00013\end{array}$ & $\begin{array}{l}0.00029 \\
0.00001 \\
0.00062 \\
0.00043 \\
0.00087\end{array}$ & $\begin{array}{l}0.00261 \\
0.00091 \\
0.00095 \\
0.00127 \\
0.00101\end{array}$ & $\begin{array}{l}0.00498 \\
0.00188 \\
0.00119 \\
0.00244 \\
0.00131\end{array}$ & $\begin{array}{r}65 \\
108 \\
118 \\
127 \\
17\end{array}$ \\
\hline
\end{tabular}


Table 6

Percentage of the Spread Due to Different Types of Default Risk Events. This table reports summary statistics for the percentages of the total CDX index spread due to the indicated Poisson processes. The percentage for the first Poisson process is given from the ratio of $\gamma_{1} \lambda_{1}$ to the total CDX index value, and similarly for the other two Poisson processes. Sample period is from October 2003 to October 2005.

\begin{tabular}{|c|c|c|c|c|c|c|c|}
\hline $\begin{array}{l}\text { Poisson } \\
\text { Process }\end{array}$ & Index & Mean & $\begin{array}{l}\text { Standard } \\
\text { Deviation }\end{array}$ & Minimum & Median & Maximum & $N$ \\
\hline First & $\begin{array}{l}\text { CDX } 1 \\
\text { CDX } 2 \\
\text { CDX } 3 \\
\text { CDX } 4 \\
\text { CDX } 5\end{array}$ & $\begin{array}{l}58.83 \\
57.70 \\
64.19 \\
71.56 \\
82.17\end{array}$ & $\begin{array}{l}2.24 \\
2.38 \\
2.26 \\
4.37 \\
1.41\end{array}$ & $\begin{array}{l}53.36 \\
54.11 \\
59.08 \\
61.57 \\
79.23\end{array}$ & $\begin{array}{l}58.43 \\
56.85 \\
64.85 \\
72.91 \\
82.79\end{array}$ & $\begin{array}{l}63.59 \\
64.44 \\
67.54 \\
80.01 \\
83.50\end{array}$ & $\begin{array}{r}65 \\
108 \\
118 \\
127 \\
17\end{array}$ \\
\hline Second & $\begin{array}{l}\text { CDX } 1 \\
\text { CDX } 2 \\
\text { CDX } 3 \\
\text { CDX } 4 \\
\text { CDX } 5\end{array}$ & $\begin{array}{l}33.34 \\
37.02 \\
28.88 \\
15.92 \\
10.48\end{array}$ & $\begin{array}{l}2.79 \\
3.17 \\
2.98 \\
7.11 \\
0.69\end{array}$ & $\begin{array}{r}29.34 \\
29.02 \\
23.65 \\
7.81 \\
9.83\end{array}$ & $\begin{array}{l}32.19 \\
38.00 \\
28.20 \\
13.24 \\
10.12\end{array}$ & $\begin{array}{l}40.24 \\
41.99 \\
34.82 \\
30.16 \\
11.71\end{array}$ & $\begin{array}{r}65 \\
108 \\
118 \\
127 \\
17\end{array}$ \\
\hline Third & $\begin{array}{l}\text { CDX } 1 \\
\text { CDX } 2 \\
\text { CDX } 3 \\
\text { CDX } 4 \\
\text { CDX } 5\end{array}$ & $\begin{array}{r}7.83 \\
5.28 \\
6.93 \\
12.52 \\
7.35\end{array}$ & $\begin{array}{l}3.03 \\
2.32 \\
1.18 \\
3.77 \\
0.84\end{array}$ & $\begin{array}{l}0.91 \\
0.06 \\
4.07 \\
5.04 \\
6.38\end{array}$ & $\begin{array}{r}7.83 \\
5.27 \\
6.86 \\
12.26 \\
7.29\end{array}$ & $\begin{array}{r}13.31 \\
10.82 \\
9.77 \\
19.97 \\
9.43\end{array}$ & $\begin{array}{r}65 \\
108 \\
118 \\
127 \\
17\end{array}$ \\
\hline
\end{tabular}


Table 7

CDX Index Tranche Pricing Errors. This table reports summary statistics for the pricing errors for the indicated CDX index tranches. The $t$-statistic for the mean is corrected for first-order serial correlation. Pricing errors are measured in basis points. The sample period is from October 2003 to October 2005

\begin{tabular}{|c|c|c|c|c|c|}
\hline Tranche & Index & Mean & $\begin{array}{l}\text { Standard } \\
\text { Deviation }\end{array}$ & $\begin{array}{r}t \text {-Statistic } \\
\text { for the Mean }\end{array}$ & $N$ \\
\hline $0-3$ Tranche & $\begin{array}{l}\text { CDX } 1 \\
\text { CDX } 2 \\
\text { CDX } 3 \\
\text { CDX } 4 \\
\text { CDX } 5\end{array}$ & $\begin{array}{r}-7.00 \\
-1.27 \\
-0.19 \\
-0.20 \\
0.02\end{array}$ & $\begin{array}{l}8.56 \\
2.18 \\
0.97 \\
1.17 \\
0.29\end{array}$ & $\begin{array}{r}-1.66 \\
-1.33 \\
-0.26 \\
-0.55 \\
0.32\end{array}$ & $\begin{array}{r}65 \\
108 \\
118 \\
127 \\
17\end{array}$ \\
\hline 3-7 Tranche & $\begin{array}{l}\text { CDX } 1 \\
\text { CDX } 2 \\
\text { CDX } 3 \\
\text { CDX } 4 \\
\text { CDX } 5\end{array}$ & $\begin{array}{r}-3.21 \\
-0.51 \\
-0.21 \\
0.00 \\
-0.03\end{array}$ & $\begin{array}{r}3.34 \\
1.21 \\
-.73 \\
1.19 \\
0.28\end{array}$ & $\begin{array}{r}-1.98 \\
-1.16 \\
-0.55 \\
0.01 \\
-0.42\end{array}$ & $\begin{array}{r}65 \\
108 \\
118 \\
127 \\
17\end{array}$ \\
\hline 7-10 Tranche & $\begin{array}{l}\text { CDX } 1 \\
\text { CDX } 2 \\
\text { CDX } 3 \\
\text { CDX } 4 \\
\text { CDX } 5\end{array}$ & $\begin{array}{r}-2.60 \\
0.03 \\
0.61 \\
-0.27 \\
0.16\end{array}$ & $\begin{array}{l}8.34 \\
3.06 \\
3.32 \\
4.53 \\
1.12\end{array}$ & $\begin{array}{r}-0.66 \\
0.04 \\
0.30 \\
-0.15 \\
0.51\end{array}$ & $\begin{array}{r}65 \\
108 \\
118 \\
127 \\
17\end{array}$ \\
\hline 10-15 Tranche & $\begin{array}{l}\text { CDX } 1 \\
\text { CDX } 2 \\
\text { CDX } 3 \\
\text { CDX } 4 \\
\text { CDX } 5\end{array}$ & $\begin{array}{l}-6.62 \\
-2.07 \\
-0.45 \\
-0.27 \\
-0.76\end{array}$ & $\begin{array}{l}8.05 \\
5.74 \\
2.77 \\
2.26 \\
0.62\end{array}$ & $\begin{array}{r}-1.67 \\
0.57 \\
-0.22 \\
-0.53 \\
-0.31\end{array}$ & $\begin{array}{r}65 \\
108 \\
118 \\
127 \\
17\end{array}$ \\
\hline 15-30 Tranche & $\begin{array}{l}\text { CDX } 1 \\
\text { CDX } 2 \\
\text { CDX } 3 \\
\text { CDX } 4 \\
\text { CDX } 5\end{array}$ & $\begin{array}{r}-8.09 \\
-2.98 \\
-0.83 \\
-0.62 \\
0.06\end{array}$ & $\begin{array}{l}1.88 \\
3.63 \\
1.90 \\
2.39 \\
0.46\end{array}$ & $\begin{array}{r}-9.13 \\
-1.66 \\
-0.64 \\
-0.72 \\
0.45\end{array}$ & $\begin{array}{r}65 \\
108 \\
118 \\
127 \\
17\end{array}$ \\
\hline
\end{tabular}


Table 8

Regression of the Standard Deviation of the Loss Distribution on the CDX Index Spread and CDX Index Dispersion. This table reports the results from the regression of the standard deviation of the loss distribution implied by the fitted model each day on the corresponding CDX index spread and the cross-sectional standard deviation of the CDS spreads for the 125 individual firms in the CDX index. The sample period is from October 2003 to October 2005.

Std.Deviation $t=a+b$ CDX $_{t}+c$ Dispersion $_{t}+\epsilon_{t}$.

\begin{tabular}{rrr|rr|rc}
\hline$a$ & $b$ & $c$ & $t_{a}$ & $t_{b}$ & $t_{c}$ & $R^{2}$ \\
\hline 0.0089 & 3.3763 & 0.8002 & 10.59 & 18.95 & 10.30 & 0.681 \\
\hline
\end{tabular}



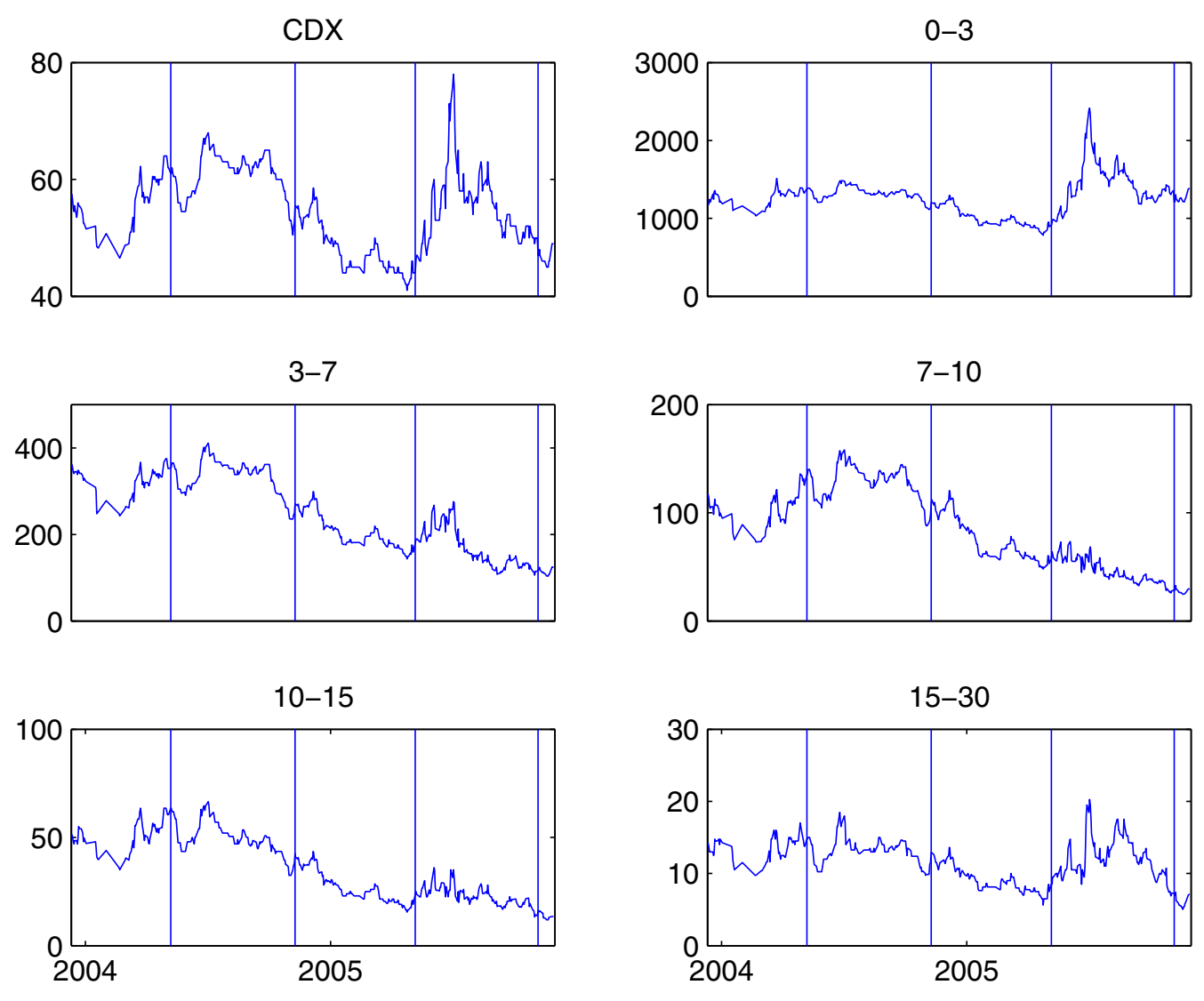

Fig. 1. CDX Index and Tranche Spreads. This figure graphs the time series of the CDX index and its tranche spreads for the October 2003 to October 2005 sample period. Spreads are in basis points. The vertical division lines denote the roll from one CDX index to the next. 


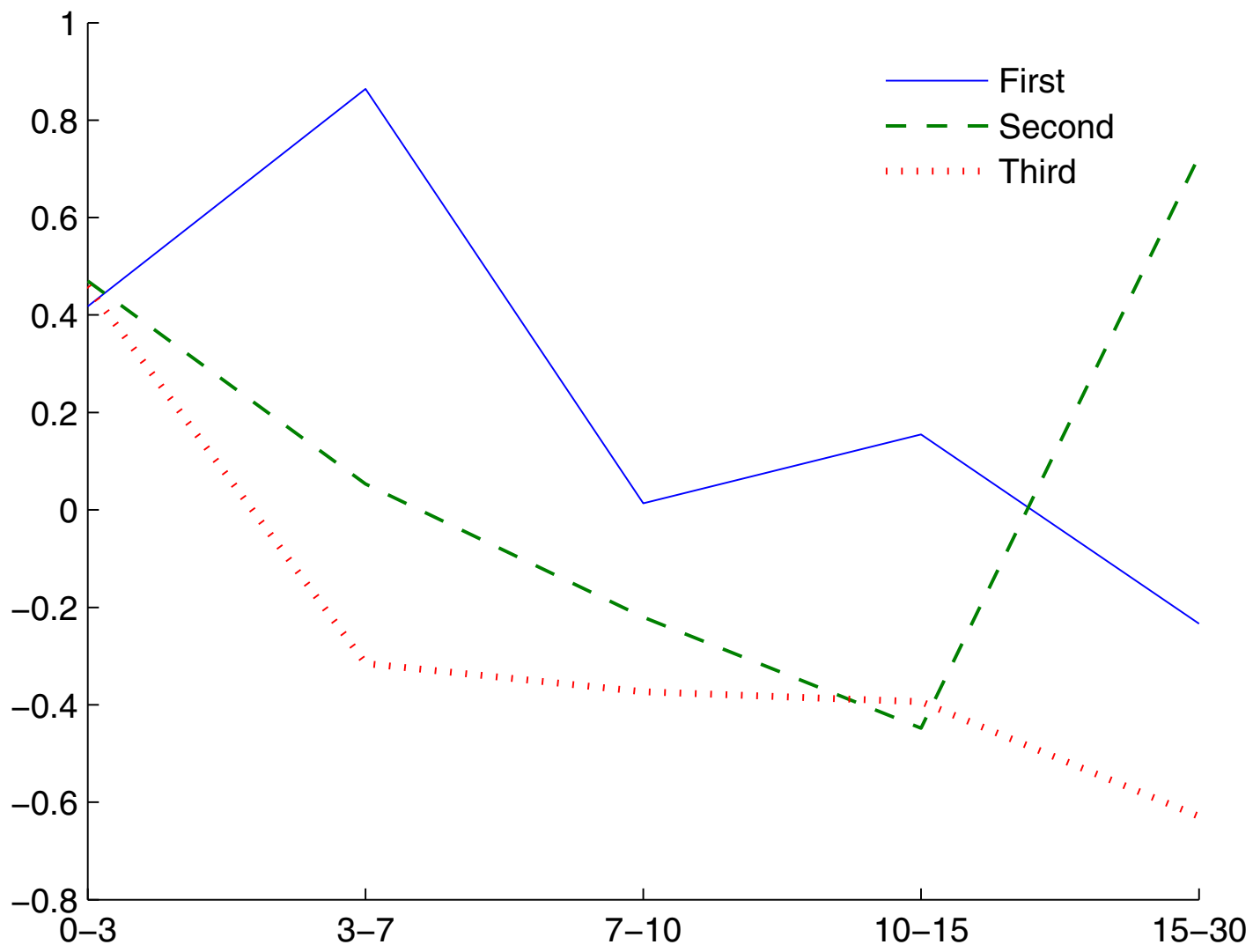

Fig. 2. Principal Components of Daily Changes in Tranche Spreads. This figure graphs the first three principal components of the daily changes in CDX tranche spreads for the October 2003 to October 2005 sample period. 
First Intensity

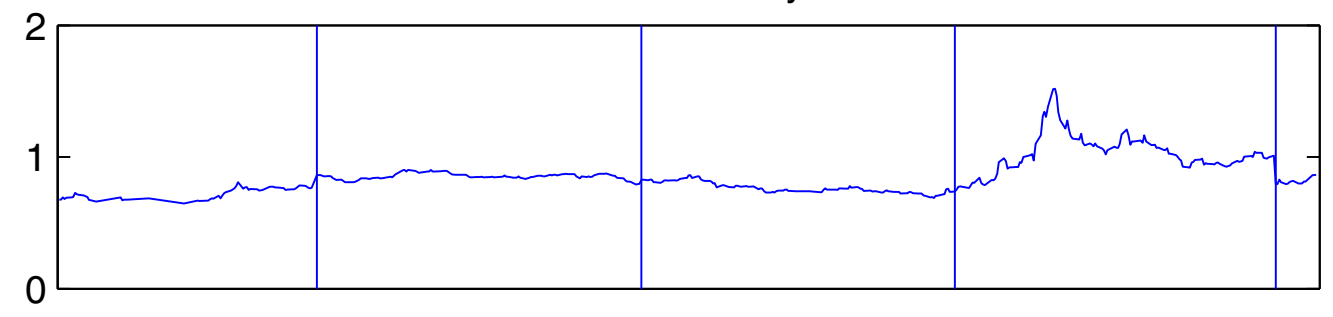

Second Intensity

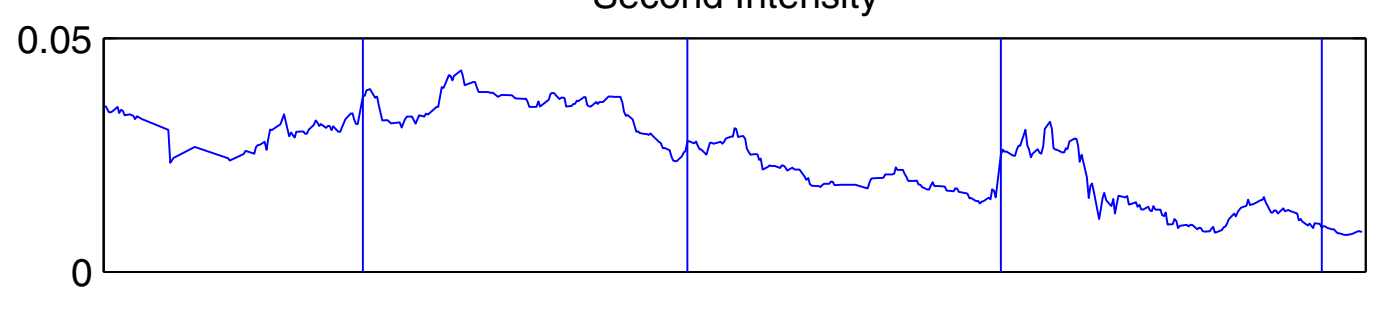

Third Intensity

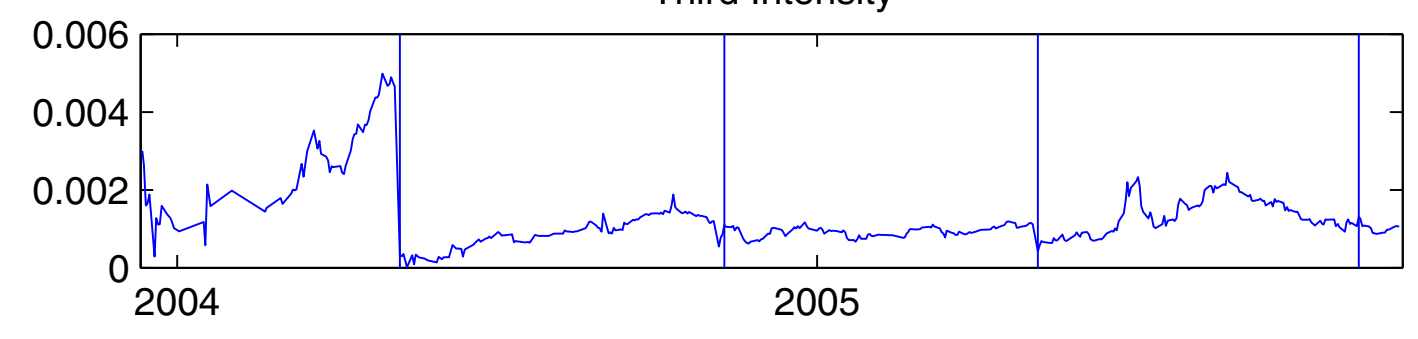

Fig. 3. Intensity Processes. This figure graphs the estimated intensity processes. The vertical division lines denote the roll from one CDX index to the next. 


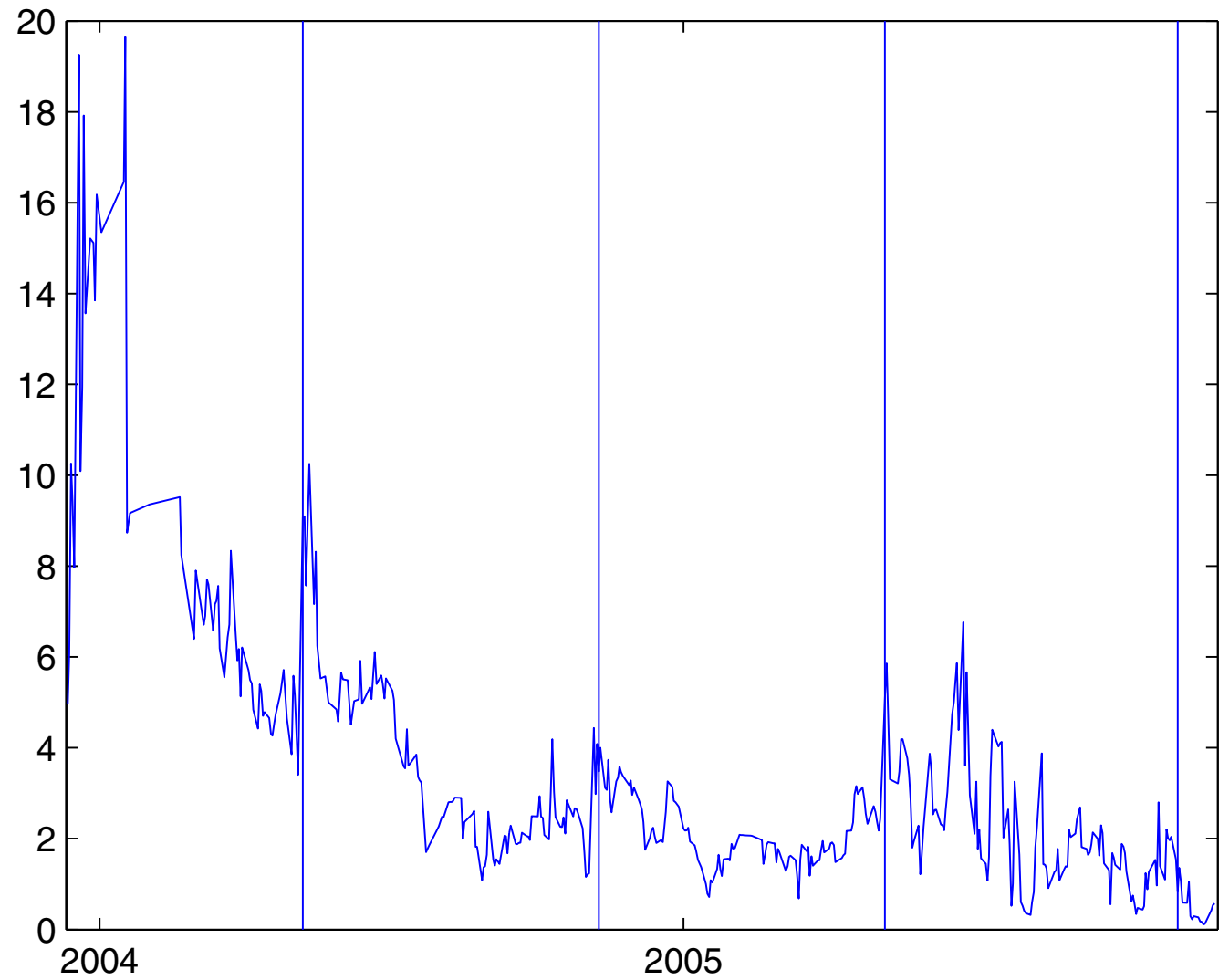

Fig. 4. Time Series of Overall RMSEs. This figure graphs the time series of daily overall root mean squared error (RMSE) from the fitting of the five CDX tranches. RMSEs are measured in basis points. The vertical division lines denote the roll from one CDX index to the next. 

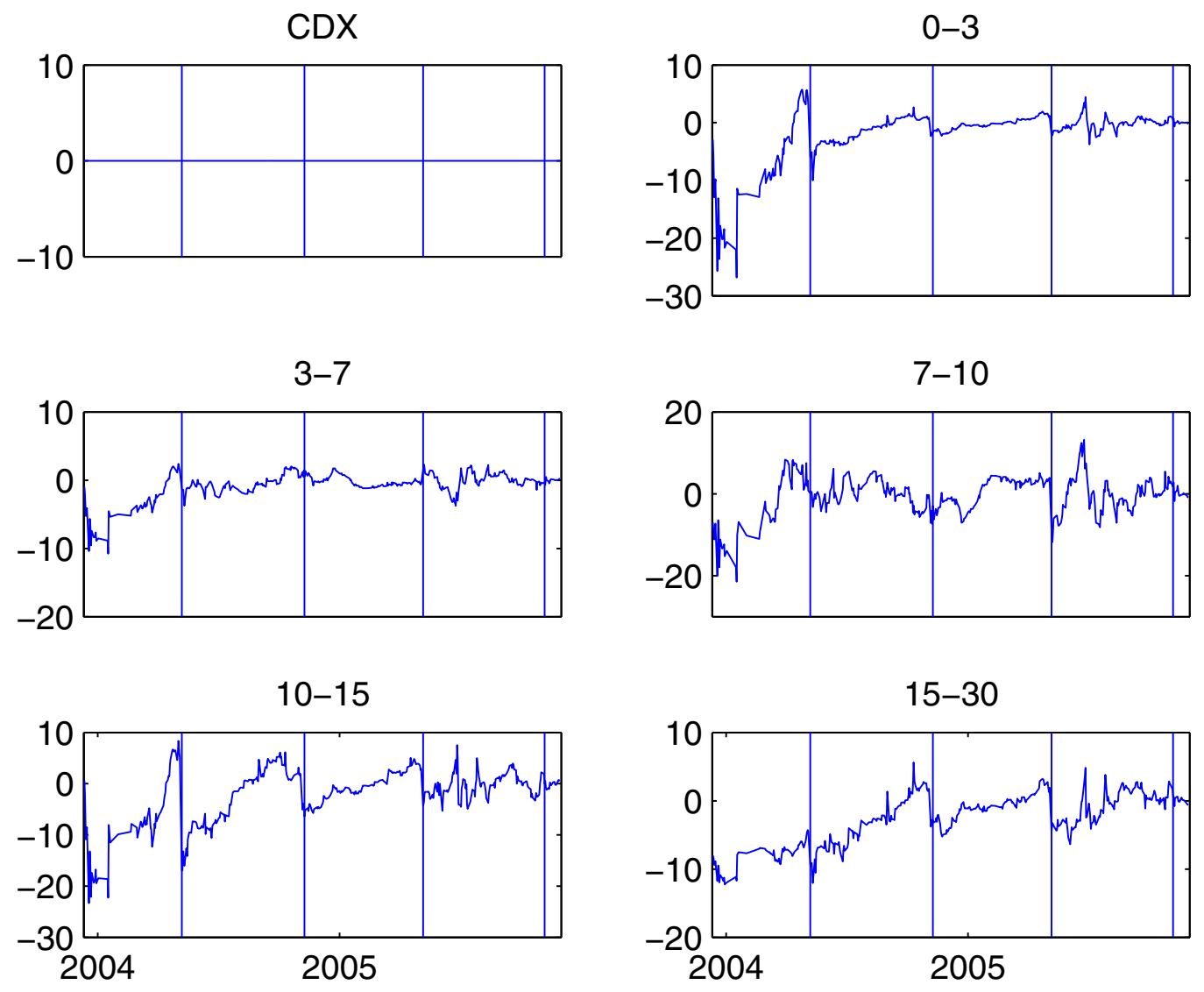

Fig. 5. Pricing Errors. This figure plots the difference between the model implied and actual market spreads for the indicated CDX tranches. Pricing errors are measured in basis points. The vertical division lines denote the roll from one CDX index to the next. 